\begin{tabular}{|l|l|}
\hline Title: & $\begin{array}{l}\text { The theoretical principles of the critical shear crack theory for punching shear } \\
\text { failures and derivation of consistent closed-form design expressions }\end{array}$ \\
\hline Authors: & Muttoni A., Fernández Ruiz M., Simões J. T. \\
\hline Published in: & Structural concrete \\
\hline DOI & $10.1002 /$ suco.201700088 \\
\hline Pages: & pp. $1-17$ \\
\hline Year of publication: & 2017 \\
\hline Type of publication: & Peer reviewed journal article \\
\hline
\end{tabular}

Please quote as:

Muttoni A., Fernández Ruiz M., Simões J. T., The theoretical principles of the critical shear crack theory for punching shear failures and derivation of consistent closed-form design expressions, Structural concrete, 2017, pp. 1-17. 


\title{
The theoretical principles of the critical shear crack theory for punching shear failures and derivation of consistent closed-form design expressions
}

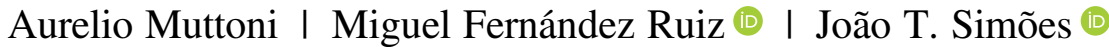

École Polytechnique Fédérale de Lausanne, School of Architecture Civil and Environmental Engineering, Station 18, CH-1015, Lausanne, Switzerland

\section{Correspondence}

João T. Simões, École Polytechnique Fédérale de Lausanne, School of Architecture Civil and Environmental Engineering, Station 18, CH-1015 Lausanne, Switzerland.

Email: joao.simoes@epfl.ch
The mechanical model of the critical shear crack theory (CSCT) has been used in the past to investigate a number of shear-related problems, such as punching of slab-column connections with and without transverse reinforcement. In this paper, a discussion on the differences and analogies between slender slabs and squat members (footings) without transverse reinforcement is presented on the basis of the CSCT. This discussion highlights how bending and shear deformations influence the opening of the critical shear crack and eventually its ability to transfer shear forces. On that basis, it is investigated and justified a power-law expression to characterize the failure criterion of the CSCT. This criterion, in combination with a suitable load-deformation relationship, can be used to derive closed-form expressions for punching shear design. The accuracy of these expressions is verified against databases of slender slabs (121 specimens) and footings (34 specimens) with consistent agreement.

\section{KEYWORDS}

closed-form design expressions, concrete structures, critical shear crack theory, experimental verification, mechanical model, punching shear

\section{1 | INTRODUCTION}

Research on punching shear and its design implications has drawn much interest of the scientific and practitioner communities. ${ }^{1-3}$ This has been motivated by a number of reported collapses ${ }^{4,5}$ and by the fact that many design expressions found in codes of practice still have an empirical nature. ${ }^{6,7}$ Following this research effort, a number of mechanically based models have been developed in the past with the aim of providing consistent design expressions for punching shear.

One of the first models with a rational basis to calculate the punching shear strength was proposed by Kinnunen and Nylander ${ }^{8}$ in the 1960s. This model considers that shear is carried by a conical strut whose failure in compression triggers the punching failure of the slab-column connection. Assuming that (a) failure of the strut occurs for a given level of the compressive tangential strain developing in the soffit of the slab in vicinity of the column and (b) by adopting a kinematics defined by a conical deformation in the outer region of the slab, Kinnunen and Nylander ${ }^{8}$ established a failure criterion as a function of the rotation of the slab (whose calculation was performed adopting a bilinear moment-curvature relationship). The rational theory of Kinnunen and Nylander ${ }^{8}$ was later adapted by other researchers and extended to footings, high strength concrete and to have consistent treatment of size effect (e.g., References 9-11).

Consistently with the principal ideas of Kinnunen and Nylander's model, Muttoni and Schwartz ${ }^{12}$ developed a rational approach to punching. The main ideas of Muttoni ${ }^{13}$ are that strains localize in a critical shear crack (Figure 1a) that governs the ability of a slab to transfer shear forces (as a function of the crack lips displacements and their roughness). ${ }^{12-14}$ This approach was also shown to be 
$217 b$

(a)

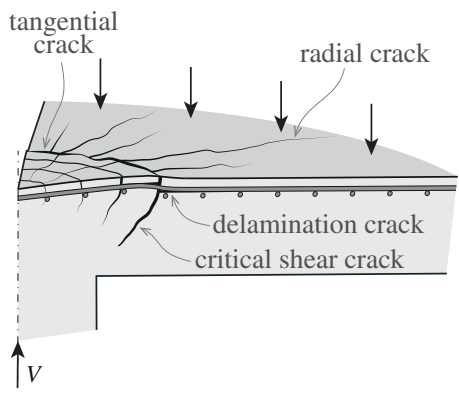

(b)

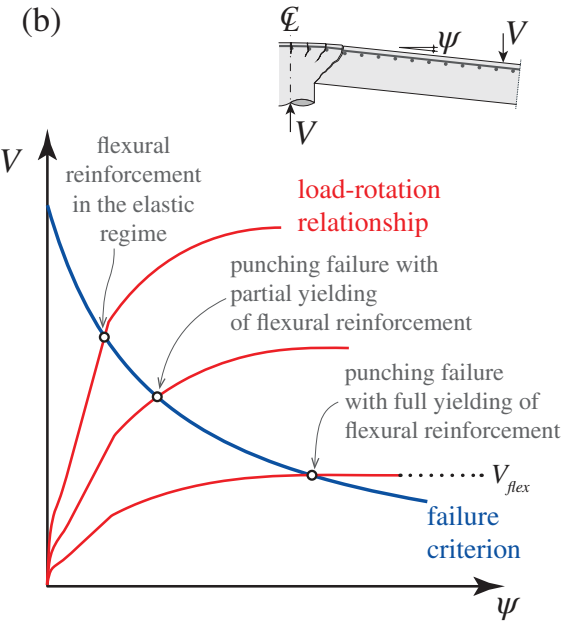

(c)

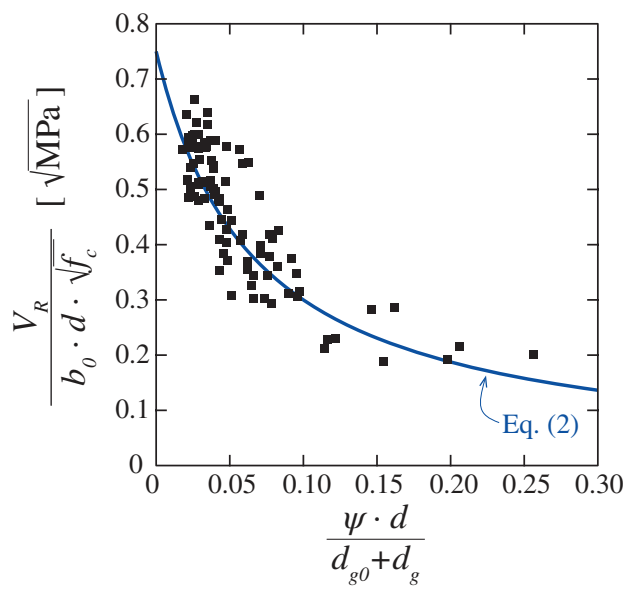

FIGURE 1 (a) Schematic representation of cracking at a slab-column connection; (b) potential punching failures; (c) failure criterion of critical shear crack theory $(\mathrm{CSCT})^{13}$ compared to tests according to the database of Muttoni ${ }^{13}$

applicable in a consistent manner to failures in shear for one-way slabs ${ }^{14}$ and for shear-reinforced slabs ${ }^{15}$ and was named as the critical shear crack theory (CSCT).

In agreement to the CSCT assumptions, and as confirmed experimentally, ${ }^{13,16}$ larger openings of the critical shear crack reduce the capacity of transferring shear forces. Thus, the punching strength and the deformation capacity of a slab-column connection at failure can be related by means of a failure criterion (Figure 1c). By intercepting the failure criterion with the load-deformation relationship, the punching shear strength and its associated deformation can be calculated, see Figure 1b.

With respect to the load-deformation relationship for slender slabs, it can be characterized by the rotation $(\psi)$ of the slab. ${ }^{13}$ Such load-rotation relationship is highly nonlinear and influenced by cracking, tension-stiffening effects, and potential reinforcement yielding, ${ }^{17}$ thus being influenced by the reinforcement amount and properties. As a consequence, failures can occur in different regimes (Figure 1b) ${ }^{16}$ : with all reinforcement remaining elastic, part of the reinforcement being yielded or even at the flexural capacity. Although detailed calculation of the load-rotation relationship can be performed (considering quadri-linear moment-curvature diagrams incorporating cracking and tension-stiffening effects), ${ }^{13}$ the use of a non-linear parabolic law (derived from the quadri-linear model ${ }^{18}$ ) has shown to be efficient for design purposes in terms of accuracy and ease of use ${ }^{13}$ :

$$
\psi=k_{m} \cdot \frac{r_{s}}{d} \frac{f_{y}}{E_{s}}\left(\frac{m_{s}}{m_{R}}\right)^{3 / 2},
$$

where $r_{s}$ refers to the distance between the axis of the supported area and the line of zero radial moment, $d$ is the effective depth, $f_{y}$ and $E_{s}$ are respectively the yield strength and the modulus of elasticity of flexural reinforcement, $m_{s}$ is the average acting bending moment in the support strip (see, e.g., Reference 19 for its definition), $m_{R}$ is the average moment capacity in the support strip, ${ }^{18}$ and $k_{m}$ is a factor whose value depends on the level of refinement used to estimate the acting bending moment (value of 1.2 for refined analysis or 1.5 otherwise). ${ }^{18}$ It can be noted that an advantage of this approach is that tailored load-rotation relationships can be developed for particular cases. ${ }^{20-24}$

With respect to the failure criterion, Muttoni and Schwartz ${ }^{12}$ considered that, for slender slabs, the opening of the critical shear crack $(w)$ could be assumed proportional to the slab rotation $\psi$ times the effective depth $d$. Thus, by assuming that $w \propto \psi \cdot d$, the following failure criterion was proposed $^{13}$ :

$$
\frac{V_{R c}}{b_{0} \cdot d \cdot \sqrt{f_{c}}}=\frac{3 / 4}{1+15 \cdot \frac{\psi \cdot d}{d_{g 0}+d_{g}}},
$$

where $b_{0}$ is the control perimeter (located at $d / 2$ from the edge of the supported area; round corners in case of square columns) and $d_{g 0}$ represents the reference aggregate size $\left(d_{g 0}=16 \mathrm{~mm}\right.$ for normal weight concrete $\left.^{13}\right)$. The term $d_{g 0}+d_{g}$ (originally introduced by Vecchio and Collins ${ }^{25}$ ) refers in fact to a reference crack roughness accounting for the maximum aggregate size $\left(d_{g}\right)$ but also for the fact that the crack surface is not perfectly planar. $^{26}$ It can also be noted that the term $\psi \cdot d$ actually accounts in a combined manner for the influence of size and strain effects. ${ }^{26}$

With respect to compact slabs or footings, the main assumptions of the CSCT have been demonstrated to be also valid (crack localization and influence of crack width and crack roughness on the capacity to transfer shear forces at the failure surface). ${ }^{27}$ Yet, in these cases, the crack kinematics at failure is more complex and shall account for shear deformations, as also demonstrated by Simões et al. ${ }^{27}$ In this paper, the mechanical model of the CSCT is presented and discussed in terms of its failure mechanism and associated stresses developing on the failure surface. The calculation of the punching strength on the basis of the 
stresses on the failure surface is also reviewed and discussed for slender members (where flexural deformations govern) based on the work of Guidotti ${ }^{28}$ and for squat members (where shear deformations govern) having as basis the works of Braestrup et $\mathrm{al}^{29}$ and Simões et al. ${ }^{30}$ On the basis of this review, it is presented how the CSCT failure criterion can be formulated to account in a general manner for both cases. The resulting failure criterion is thereafter used in combination with the load-deformation relationship to calculate the punching strength in a closed-form manner. It is also shown that the closed-form expression derived from the mechanical model of CSCT can be extended in a very simple manner to account for other effects, as membrane action and slab continuity.

These closed-form expressions are very convenient for design and assessment purposes, allowing a direct calculation of the punching strength and providing the designer with a clear view of the role of the various parameters implied. The results obtained are compared with databases of slabs and footings showing consistent agreement.

\section{2 | THE MECHANICAL MODEL OF CSCT FOR PUNCHING SHEAR}

\section{1 | Failure mechanism and associated internal} stresses

Two-way slabs develop radial and tangential cracking due to the presence of respectively tangential and radial bending moments in the supported area (see Figure 1a). Due to the presence of shear forces, the tangential cracks in the region of the column develop in an inclined manner, disturbing the inclined compression strut carrying shear. ${ }^{13}$

The mechanical model of the CSCT considers that crack localization occurs in a single crack (named as critical shear crack), and that the capacity of the critical shear crack to transfer shear forces depends upon the displacements between crack lips and their roughness. ${ }^{12-14}$
Calculation of the punching resistance can be performed on the basis of the assumptions by defining a critical shear crack composed of two different segments with different phenomenological behaviors, refer Figure $2 \mathrm{a}$ and b. Segment A corresponds to the crack originated by bending and segment B develops between the edge of the column and the segment A. With respect to segment A, it corresponds to a crack where a mixed-mode (opening and sliding) response occurs, while segment $\mathrm{B}$ behaves potentially as a shear band (with smeared cracking, eventually leading to coalescence in a single crack, Figure $2 b$ and $c$ ).

The kinematics of the critical shear crack in both segments can be defined as a function of the displacements normal and parallel to the crack lips, as for instance shown in Simões et al. ${ }^{30}$ Such kinematics results from the vector addition of the initial flexural crack opening (function of the slab rotation $\psi$ ) and of the shear deformations (characterized by the displacement $\delta$ occurring with a variable angle $\gamma$ with respect to the critical shear crack, see Figure 2b). The general kinematics of the critical shear crack considers therefore a combination of both rotational and translational displacements. The extent of the two regimes developing along the critical shear crack previously mentioned, the kinematics ( $\psi, \delta$ and $\gamma$ ) and the shape of the critical shear crack depend significantly on mechanical and geometrical properties. As a consequence, also the resulting stresses developing along the critical shear crack are a function of the referred variables. The slenderness of the member is probably one of the most influencing parameters with this respect. ${ }^{27}$ In the following, previous works used to investigate suitable kinematics and resulting internal stresses based on the CSCT mechanical model for slender slabs and squat members (footings) are presented and discussed.

\section{2 | Application to slender members}

The case of slender slabs with medium to large rotations was investigated in the frame of CSCT by Guidotti. ${ }^{28}$ As shown in Figure 3a, Guidotti ${ }^{28}$ considered a simplified shape for the critical shear crack developing between the (a)

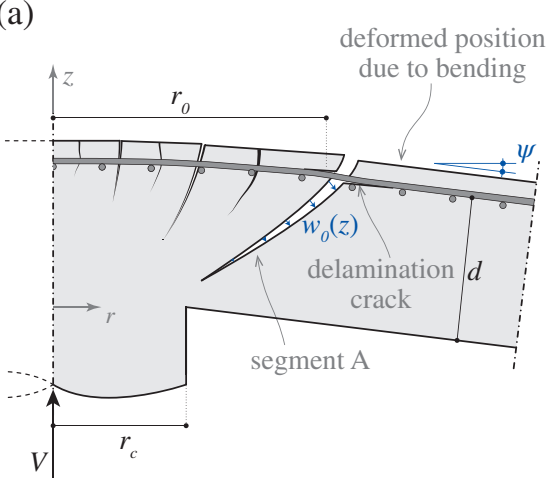

(b)

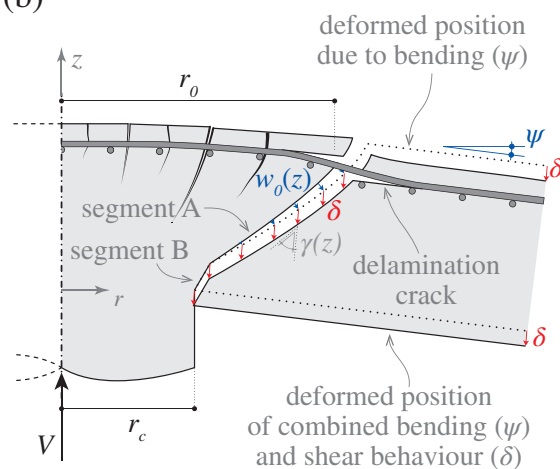

(c)

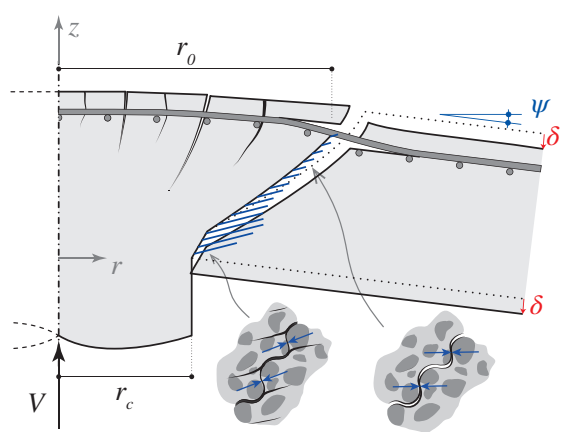

FIGURE 2 Mechanical approach of the critical shear crack theory (CSCT) for punching shear failures: (a) general kinematics due to flexural deformation; (b) general kinematics prior to failure; (c) schematic representation of stresses developing along failure surface with inclined strut carrying shear function of the opening $w$ and roughness of the critical shear crack 
edge of the column and the level of the flexural reinforcement with a constant inclination of $\beta=45^{\circ}$ (corresponding only to segment A of Figure 2). The resulting kinematics in this case $^{28}$ is composed by a rotation leading to a crack opening normal to the crack lips, followed by a crack sliding $\delta$ (developing with a constant angle $\gamma$ with respect to the crack lips), see Figure $3 a$ and $b$.

For such failure mechanism, the potential shear-transfer contributions developing along the failure surface and contributing to the punching shear strength can be calculated. They correspond to the aggregate interlock (calculated by Guidotti $^{28}$ according to Walraven ${ }^{31}$ ), residual tensile strength (calculated according to Hordijk ${ }^{32}$ ) and dowelling action (that can be neglected compared to the others due to the development of the spalling cracks, according to Guidotti). ${ }^{28}$ With respect to the aggregate interlock contribution, Guidotti ${ }^{28}$ considered a consistent kinematics at failure (initial crack opening $w_{0}$ developing before the crack sliding $\delta$ taking place, refer Figure $3 \mathrm{~b}-\mathrm{d}$ for kinematics and calculated shear and normal stresses). It should be noted that, as shown in Figure $3 \mathrm{c}$ and d, crack sliding $\delta$ is required to activate the aggregate interlock stresses.

Figure 4a shows the punching shear strength calculated under the assumptions of Guidotti ${ }^{28}$ for a general case $\left(h=0.25 \mathrm{~m} ; d=0.21 \mathrm{~m} ; f_{c}=40 \mathrm{MPa} ; d_{g}=16 \mathrm{~mm}\right.$ and $\rho=0.75 \%)$ as a function of the rotation of the slab. Also,

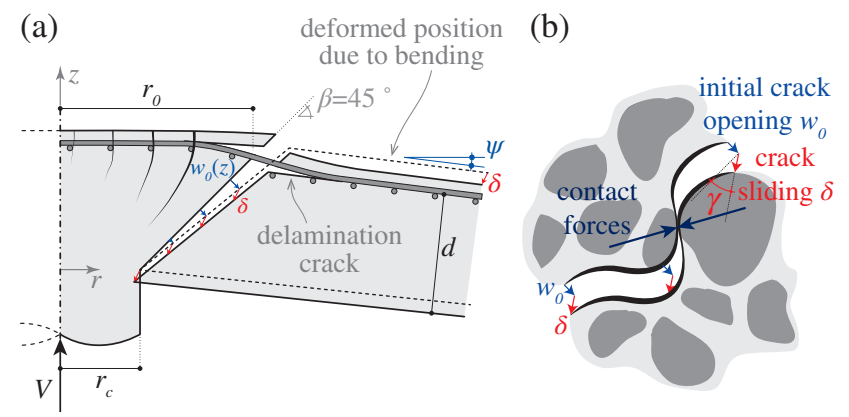

(c)

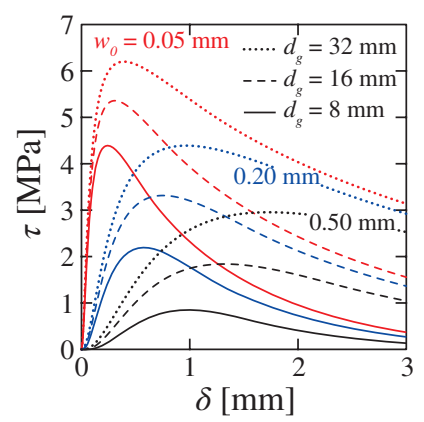

(d)

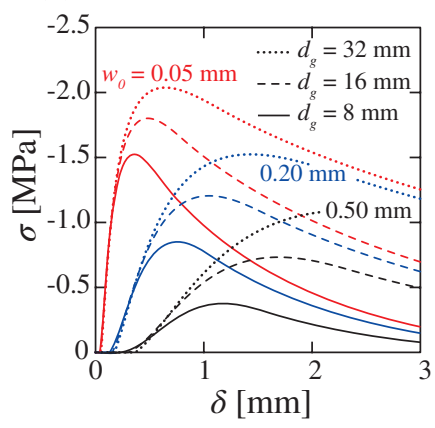

FIGURE 3 Mechanical model of Guidotti ${ }^{28}$ for the calculation of punching shear strength of slender slabs in the frame of the critical shear crack theory (CSCT): (a) shape and kinematics of the crack at failure; (b) detail of crack kinematics; (c) normal; and (d) shear stresses for different initial crack openings $\left(w_{0}=0.05,0.20\right.$, and $\left.0.50 \mathrm{~mm}\right)$ and aggregate sizes $\left(d_{g}=8,16\right.$, and $\left.32 \mathrm{~mm} ; f_{c}=30 \mathrm{MPa} ; \gamma=30^{\circ}\right)$ as a function of the crack sliding calculated according to Guidotti ${ }^{28}$ the resulting internal stresses developing along the critical shear crack are shown in Figure 4a for three different rotations: low, medium, and high rotations. A decay of shear strength with the increase of the crack width can be clearly observed, as a result of the decrease of the capacity of the different shear-transfer actions (due to loss of contact in the upper part of the slab and by the softening in the lower part due to increasing crack opening). It can be noted that the resulting stress state can be described by an inclined compression strut whose strength is thus strain and size dependent. This result is in agreement with the CSCT assumptions as well as those of Kinnunen and Nylander. ${ }^{8}$ As shown in Figure $4 \mathrm{a}$, the hyperbolic failure criterion proposed by Muttoni $^{13}$ and defined in Equation (2) approximates fairly well the results predicted by the mechanical model of CSCT presented by Guidotti. ${ }^{28}$

The approach of Guidotti ${ }^{28}$ also allows validating the assumption of the CSCT for slender slabs that the crack width $w$ can be assumed to be correlated to the product $\psi d$. This fact is shown in Figure $4 \mathrm{~b}$ where the numerical results from Guidotti ${ }^{28}$ for the crack width $w$ measured at peak load and at $d / 2$ from the edge of the column are shown. It can be noted that the crack width at failure, accounting for the development of the flexural and shear deformations ( $\psi$ and $\delta$ ), follows a trend which is almost linear. This result is physically justified as larger crack openings require larger shear deformations $\delta$ to mobilize aggregate interlock forces and thus both parameters are related.

\section{3 | Application to footings and squat members}

For small rotations, the approach of Guidotti ${ }^{28}$ is not necessarily governing, as other shapes of the failure surface and associated kinematics may limit the punching shear strength. This topic has been investigated in the past (for instance by Braestrup et $\mathrm{al}^{29}$ on the basis of limit analysis and more recently by Simões et $\mathrm{al}^{30}$ ) showing that for footings or squat members, flexural deformations play a more secondary role. ${ }^{27}$ In these cases, the behavior is mostly controlled by segment B in Figure 2b, where the shear deformations are governing.

According to Braestrup et al, ${ }^{29}$ a kinematically admissible mechanism in these cases consists of a vertical translation of the outer portion of the member (Figure 5a, also used by other researchers ${ }^{33-36}$ ). It is interesting to note that the failure mechanism originally proposed by Braestrup et $\mathrm{al}^{29}$ corresponds to a limit situation of the mechanical model of CSCT where only segment B develops. Also, in agreement to the CSCT assumptions, and as discussed by Simões et $\mathrm{al}^{30}$ the capacity of the governing failure surface to transfer shear forces in these cases is affected by its state of deformations (crack opening). The punching strength calculated accounting for such failure mechanism and by adopting a rigid-plastic constitutive law for concrete (Figure $5 \mathrm{~b}$ and c) can be consulted in Reference 29 It can be in a general 
(a)

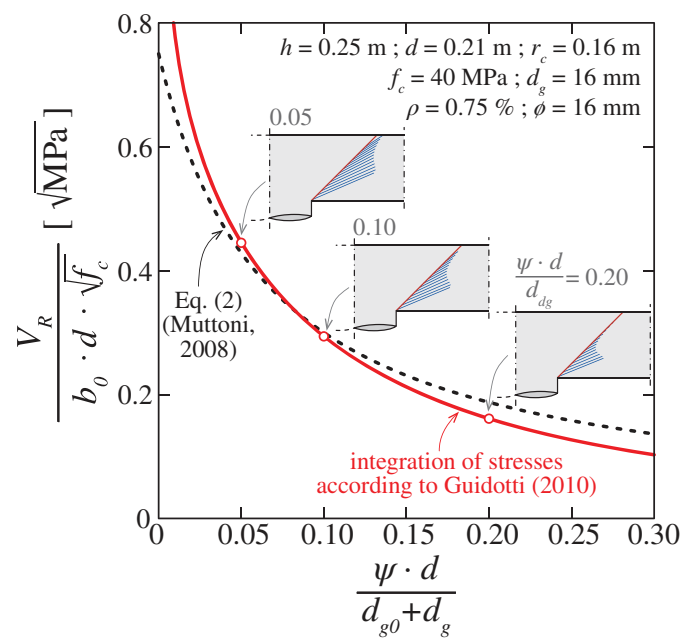

(b)

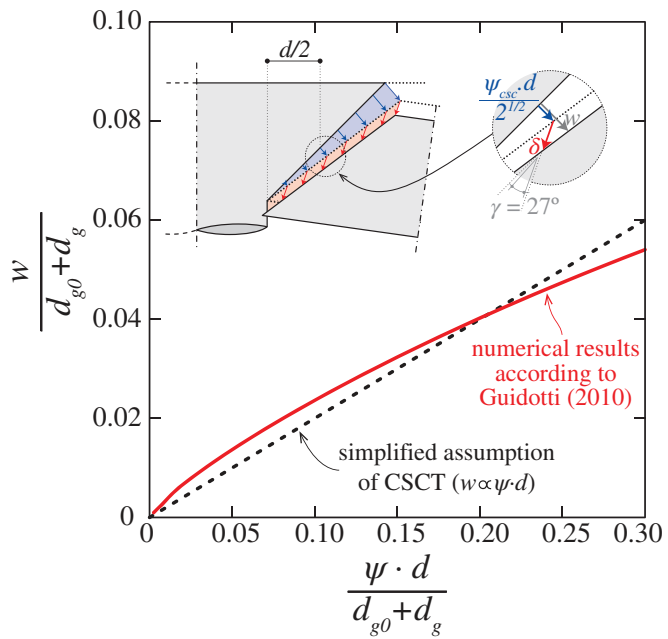

FIGURE 4 Numerical results of Guidotti ${ }^{28}$ for an example: (a) comparison of numerical failure criterion with critical shear crack theory (CSCT) hyperbolic (Equation (2)) and power-law (Equation (6)) failure criteria with representation of the resultant of stresses developing along the failure surface for different rotations; (b) crack opening-rotation relationship numerically obtained and comparison to simplified assumption of Muttoni ${ }^{13}$

manner expressed as (see Figure 5d using axis of ordinates on the left, neglecting the capacity of the concrete cover):

$$
V_{R}=k_{v} \cdot b_{0} \cdot d \cdot f_{c e}
$$

where $k_{v}$ is a parameter which depends upon the member slenderness (function of $r_{c}, d$, and $r_{0}$ ) and the friction angle of concrete $(\varphi)$. It shall be noted that in Equation (3), the punching strength $\left(V_{R}\right)$ is also dependent on the effective compressive strength of concrete $\left(f_{c e}\right)$. This parameter accounts for the brittleness of concrete in compression and for the influence of the state of deformations as proposed by Nielsen and Hoang ${ }^{37}$ :

$$
f_{c e}=f_{c} \cdot \eta=f_{c} \cdot \eta_{f c} \cdot \eta_{w},
$$

where $\eta$ is a global effectiveness factor that, for this case, can be split into two distinct ones: $\eta_{f c}$ and $\eta_{w}$ referring to the effectiveness factors accounting for concrete brittleness and the state of deformations, respectively. With respect to the concrete brittleness in compression, previous works on the application of limit analysis for the case of punching shear (e.g., References 37-40) have suggested adopting a relationship $\eta_{f_{c}}=k_{f_{c}} / \sqrt{f_{c}}$. With respect to $\eta_{w}$, its value may depend on the state of strains ${ }^{30}$ and also on the size of the member. ${ }^{37}$

For practical purposes, the maximum achievable punching strength can therefore be calculated as (see Figure $5 \mathrm{~d}$ using axis of ordinates on the right):

$$
V_{R}=k_{v} \cdot k_{f c} \cdot \eta_{w} \cdot d \cdot b_{0} \cdot \sqrt{f_{c}} .
$$

It can be noted that this equation presents the same parameters $d, b_{0}$, and $\sqrt{f_{c}}$ as that of the CSCT failure criterion (refer Equation (2)). Additionally, it considers that the shear capacity is affected by the size and strains of the member, both parameters influencing the opening of the critical shear (a)

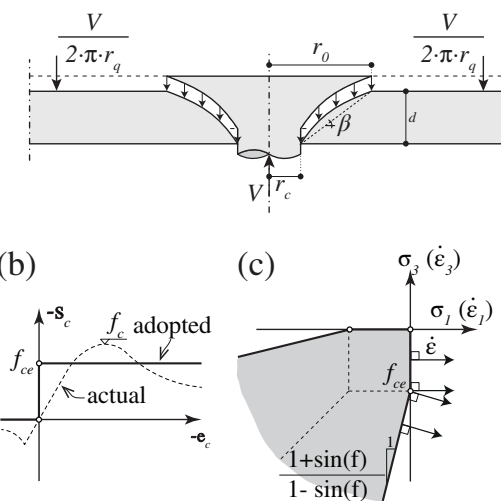

(d)

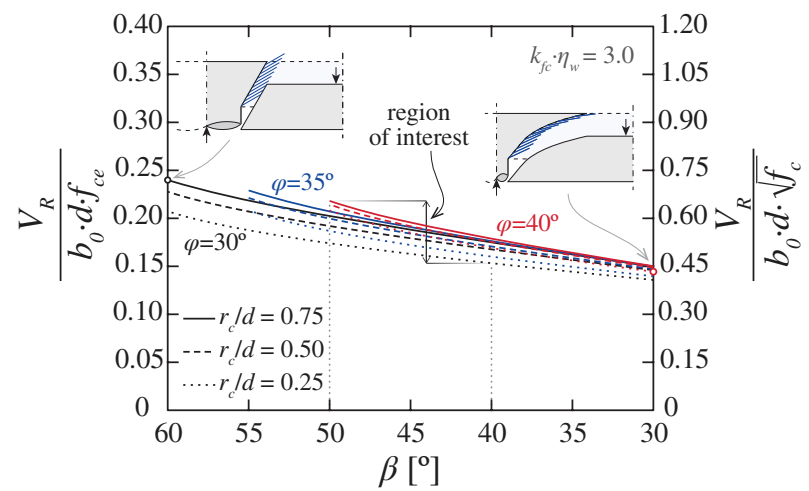

FIGURE 5 Punching shear strength according to upper bound theorem of limit analysis by Braestrup et $\mathrm{al}^{29}$ : (a) adopted failure mechanism; (b) rigidplastic behavior considered for concrete; (c) Mohr-Coulomb yield criterion adopted for concrete with tension cut-off; (d) punching shear strength as a function of secant inclination of the failure surface $\beta$ and of the concrete friction angle $\varphi$ 
6 176

crack as considered in the CSCT mechanical model. As shown in the results of Figure $5 \mathrm{~d}$, since the variation of the maximum achievable punching shear strength is relatively limited, the consideration of a constant value for the multiplication of the parameters $k_{v} \cdot k_{f c} \cdot \eta_{w}$ equal to 0.55 is a reasonable simplification for design purposes.

\section{I CONSIDERATIONS ON THE FAILURE CRITERION OF THE CSCT}

Calculating the punching response on the basis of the mechanical model of the CSCT by performing a numerical integration of the resulting stresses on the failure surface $^{28,30}$ is a general but not suitable approach for design purposes. To provide a simpler design approach, it can be observed that, when normalized in terms of the main physical parameters of the CSCT mechanical model, both numerical integrations ${ }^{28,30}$ and test results remain within a narrow failure region (Figure 1c). These results indicate a decrease of the normalized strength for increasing normalized crack opening. On that basis, Muttoni ${ }^{13}$ proposed a simplified expression for the failure criterion with a hyperbolic shape (refer Equation (2) and Figure 1c).

This hyperbolic failure criterion and the parabolic loadrotation relationship (Equation (1)) can be used in a simple and direct manner for design using the Levels-ofAproximation approach. ${ }^{13,18,19,41-43}$ This design approach has proven to be general and efficient for design and to suitably account for size and strain effects. ${ }^{17}$ Yet, closed-form solutions (which may enhance the usability of the theory for design and assessment and also clarify the significance of the various mechanical and geometrical parameters on the punching strength) cannot be obtained by using the previous Equations (1) and (2).
Despite the advantages of the hyperbolic failure criterion, a more general expression could be formulated by accounting for the two relatively distinct behaviors described before (failures governed by flexural deformations $^{28}$ and failures governed by shear deformations ${ }^{30}$ ) in order to address in a more clear manner the differences between slender and squat members. A proposal with this respect has been recently presented by Muttoni and Fernández Ruiz, ${ }^{44}$ by considering the following power-law expression:

$$
V_{R c}=V_{R c, 0} \cdot\left(\frac{d_{d g}}{25 \cdot \psi \cdot d}\right)^{2 / 3} \leq V_{R c, 0},
$$

where $d_{d g}$ refers to the reference value of roughness of the crack and $V_{R c, 0}$ refers to the maximum achievable punching shear strength. With respect to term $d_{d g}$, it can be calculated as:

$$
d_{d g}=d_{g 0}+d_{g} \cdot \min \left(\left(\frac{60}{f_{c}}\right)^{2}, 1\right) \leq 40 \mathrm{~mm},
$$

where $d_{g O}$ is the reference roughness value of the crack, which can be adopted equal to $16 \mathrm{~mm}$ for normal concrete. This term for the roughness is thus consistent to that previously assumed by the CSCT (refer Equation (2)), but accounts additionally for two effects: (a) the limit on the positive influence of aggregate size on the shear-transfer capacity for large aggregate sizes (limit to $40 \mathrm{~mm}$ in accordance to Sherwood et $\mathrm{al}^{45}$ ) and (b) the reduced roughness of the surface for high strength concrete (fracture developing through the aggregates). ${ }^{46}$

With respect to term $V_{R c, 0}$, its value can be calculated based on Equation (5) as follows:

$$
V_{R c, 0}=0.55 \cdot b_{0} \cdot d \cdot \sqrt{f_{c}}
$$
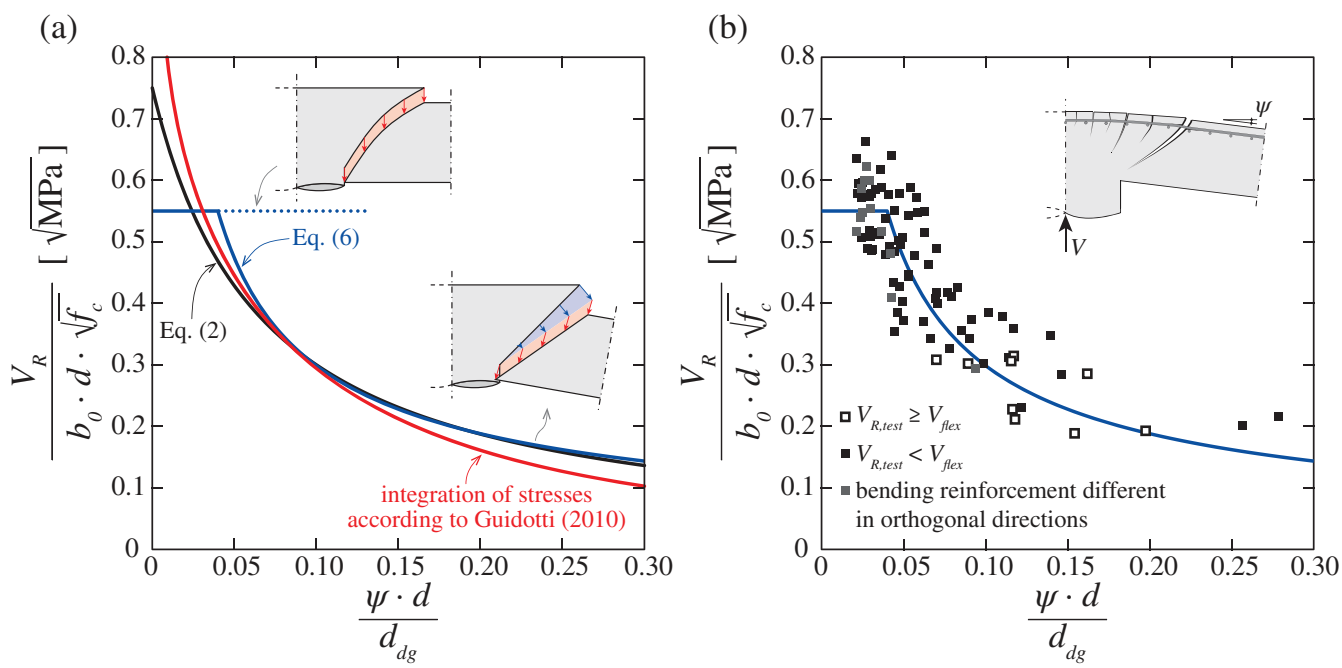

FIGURE 6 Comparison of power-law failure criterion of critical shear crack theory (CSCT) (Equation (6)) with: (a) hyperbolic failure criterion (Equation (2)) and case of Figure 4; (b) with experimental results of database of Muttoni ${ }^{13}$ 
It can be noted that this value is considered constant, although according to Equation (5) a dependency on the crack width may result. Such dependency allows for a smooth transition between both regimes, but will be neglected for simplicity reasons. The power-law failure criterion defined in Equations (6) and (8) is compared in Figure $6 \mathrm{a}$ to the strength calculated according to the approach by Guidotti ${ }^{28}$ (for the same case as presented in Figure 4). It can be noted that the simplified failure criterion finely agrees with the numerical integration of stresses and also yields close results to those of the hyperbolic failure criterion of Equation (2). In addition, the power-law failure criterion is compared in Figure $6 \mathrm{~b}$ with the experimental results of the database presented by Muttoni. ${ }^{13}$ It can be seen that for low rotations, the strength limit $\left(V_{R c 0}\right)$ is governing whereas for large rotations the power law is limiting the strength and deformation capacity. When compared to tests, the scatter is low (comparable to that of the hyperbolic failure criterion, Figure 1c) with all experimental results concentrated within a narrow region.

\section{I CLOSED-FORM SOLUTION OF THE CSCT}

\section{1 | Development of closed-form expressions for elements without transverse reinforcement}

The failure criterion presented in Equation (6) can be used to calculate the failure load in combination with the parabolic load-rotation relationship (Equation (1)) yielding closed-form solutions of the punching resistance. ${ }^{44}$ This can be done by introducing the rotation as a function of the acting shear force Equation (1) into Equation (6) and assuming $m_{s} / m_{R}=V_{R c} / V_{\text {flex }}$ :

$$
V_{R c}=V_{R c, 0} \cdot\left(\frac{V_{f l e x}}{V_{R c}}\right) \cdot\left(\frac{d_{d g}}{25 \cdot k_{m} \cdot d} \cdot \frac{d}{r_{s}} \cdot \frac{E_{s}}{f_{y}}\right)^{2 / 3} \leq V_{R c, 0},
$$

which leads to:

$$
V_{R c}=\sqrt{V_{R c, 0} \cdot V_{f l e x}} \cdot\left(\frac{d_{d g}}{25 \cdot k_{m} \cdot r_{s}} \cdot \frac{E_{s}}{f_{y}}\right)^{1 / 3} \leq V_{R c, 0} .
$$

The punching strength results thus a function of the maximum shear capacity $\left(V_{R c, 0}\right)$ and the flexural strength $\left(V_{\text {flex }}\right.$, shear force associated with full yielding of all radial and tangential flexural reinforcement ${ }^{13}$ ) as well as of other parameters characterizing roughness, size and strain effects. In addition, the deformation capacity at failure can also be calculated from Equations (1) and (10) (assuming $m_{s} / m_{R}=$ $\left.V_{R c} / V_{\text {flex }}\right)$ as:

$$
\psi_{R c}=\left(\frac{k_{m}}{25} \cdot \frac{r_{s}}{d} \cdot \frac{d_{d g}}{d} \cdot \frac{f_{y}}{E_{s}}\right)^{1 / 2} \cdot\left(\frac{V_{R c, 0}}{V_{\text {flex }}}\right)^{3 / 4} \leq k_{m} \cdot \frac{r_{s}}{d} \cdot \frac{f_{y}}{E_{s}} \cdot\left(\frac{V_{R c, 0}}{V_{f l e x}}\right)^{3 / 2}
$$

For design purposes, the calculation of the flexural strength of the slab $\left(V_{\text {flex }}\right)$ can be simplified assuming the following relationship between the flexural strength and the moment capacity ${ }^{13}$ :

$$
V_{\text {flex }}=a \cdot m_{R},
$$

where parameter $a$ relates the flexural strength to sectional moment capacity (it can be taken as 8 for inner columns according to Muttoni ${ }^{13}$ ), and $m_{R}$ can be calculated as:

$$
m_{R}=d^{2} \cdot \rho \cdot f_{y} \cdot\left(1-\frac{\rho \cdot f_{y}}{2 \cdot f_{c p}}\right),
$$

where $f_{c p}$ refers to the plastic compressive strength of concrete in uniaxial compression, calculated as $f_{c p}=f_{c}\left(30 / f_{c}\right)^{1 / 3}$ $\leq f_{c}$ (accounting for the influence of the concrete brittleness in compression). ${ }^{47}$ In order to develop simple closed-form design expressions, Equation (13) can be approximated in the following manner ${ }^{44}$ :

$$
m_{R}=k_{1} \cdot d^{2} \cdot\left(\rho \cdot f_{y}\right)^{k_{2}} \cdot f_{c}^{1-k_{2}}
$$

with $k_{1}=0.75$ and $k_{2}=0.9$. Using the relationships established in Equations (12) and (14), the flexural strength $V_{\text {flex }}$ can thus be rewritten as:

$$
V_{\text {flex }}=a \cdot 0.75 \cdot d^{2} \cdot \rho^{0.9} \cdot f_{y}^{0.9} \cdot f_{c}^{0.1} .
$$

Furthermore, by replacing Equation (15) into (10) yields:

$$
\begin{aligned}
\frac{V_{R c}}{b_{0} \cdot d}= & (0.55 \cdot 0.75)^{0.5} \cdot b_{0}{ }^{-0.5} \cdot d^{0.5} \cdot f_{c}^{0.25} \cdot a^{0.5} \cdot\left(\rho \cdot f_{y}\right)^{0.45} \cdot f_{c}^{0.05} \\
& \cdot\left(25 \cdot k_{m} \cdot f_{y}\right)^{-1 / 3} \cdot\left(\frac{d_{d g}}{r_{s}} \cdot E_{s}\right)^{1 / 3} \leq 0.55 \cdot \sqrt{f_{c}}
\end{aligned}
$$

which eventually leads to:

$$
\frac{V_{R c}}{b_{0} \cdot d}=k_{3} \cdot \sqrt{a \cdot \frac{d}{b_{0}}} \cdot\left(E_{s} \cdot \rho \cdot f_{c} \cdot \frac{d_{d g}}{r_{s}}\right)^{1 / 3} \leq 0.55 \cdot \sqrt{f_{c}},
$$

where $k_{3}=(0.55 \cdot 0.75)^{0.5} \cdot\left(25 \cdot k_{m}\right)^{-1 / 3} \cdot f_{c}^{-0.033}\left(\rho \cdot f_{y}\right)^{0.117}$ can be approximated as $k_{3}=0.225\left(k_{m}=1.2, f_{c} \approx 30 \mathrm{MPa}, \rho\right.$. $f_{y} \approx 5 \mathrm{MPa}$; low values of the exponents of $f_{c}, \rho$, and $f_{y}$ lead to a small influence of these variables on the value of $k_{3}$ ). Considering a constant modulus of elasticity $E_{s}$ $=200,000 \mathrm{MPa}$, Equation (17) can finally be written as:

$$
V_{R c}=k_{b} \cdot\left(100 \rho \cdot f_{c} \cdot \frac{d_{d g}}{r_{s}} \cdot\right)^{1 / 3} \cdot b_{0} \cdot d \leq 0.55 \cdot b_{0} \cdot d \cdot \sqrt{f_{c}},
$$

where the coefficient $k_{b}$ can be computed as follows:

$$
k_{b}=\sqrt{8 \cdot a \cdot \frac{d}{b_{0}}} \geq 1 .
$$

This coefficient accounts for the effective depth-tocontrol perimeter ratio as well as for parameter $a$ (defined in 
TABLE 1 Summary of database containing 121 specimens without transverse reinforcement: $r_{c}$ - radius of a circular column; $c$ - side length of a square column; $d$-effective depth; $f_{c}$ —cylinders concrete compressive strength; $f_{y}$-yielding strength of flexural reinforcement; $d_{g}$ —maximum aggregate size; $B$ size of the slab along orthogonal directions

\begin{tabular}{|c|c|c|c|c|c|c|c|c|c|}
\hline Authors & $\begin{array}{l}\text { Number of } \\
\text { tests }\end{array}$ & $B(\mathbf{m})$ & $d(\mathbf{m})$ & $r_{c}(\mathbf{m})$ & $c(\mathbf{m})$ & $f_{c}$ (MPa) & $d_{g}(\mathrm{~mm})$ & $\rho(\%)$ & $f_{y}(\mathrm{MPa})$ \\
\hline Elstner and Hognestad ${ }^{55}$ & 19 & 1.829 & $0.114-0.118$ & - & $0.254-0.356$ & $12.8-50.6$ & $25.4-38.1$ & $1.15-3.70$ & $321-409$ \\
\hline Kinnunen and Nylander ${ }^{8}$ & 10 & 1.840 & $0.117-0.128$ & $0.075-0.150$ & - & $24.2-31.0$ & 32 & $0.65-1.50$ & $434-461$ \\
\hline $\mathrm{Moe}^{56}$ & 7 & 1.829 & 0.114 & - & $0.152-0.254$ & $22.1-26.5$ & $9.5-38.1$ & $1.05-1.14$ & $328-482$ \\
\hline Schaefers $^{57}$ & 2 & 1.960 & $0.113-0.170$ & 0.105 & - & $21.3-27.1$ & 32 & $0.55-0.83$ & 450 \\
\hline Tolf $^{58}$ & 8 & $1.270-2.540$ & $0.098-0.200$ & $0.063-0.125$ & - & $22.6-28.2$ & $16-32$ & $0.34-0.81$ & $657-720$ \\
\hline Hallgren ${ }^{9}$ & 7 & 2.540 & $0.194-0.202$ & 0.125 & - & $84.1-108.8$ & 18 & $0.33-1.19$ & $596-643$ \\
\hline Ramdane $^{59}$ & 12 & 1.700 & $0.098-0.100$ & 0.075 & - & $26.9-101.8$ & $10-20$ & $0.58-1.28$ & $550-650$ \\
\hline Hassanzadeh $^{60}$ & 1 & 2.540 & 0.199 & 0.125 & - & 28.4 & 18 & 0.80 & 493 \\
\hline Sistonen $^{61}$ & 10 & $1.770-2.470$ & $0.170-0.177$ & $0.101-0.451$ & - & $19.0-25.8$ & 16 & $0.45-1.17$ & $576-621$ \\
\hline Birkle $^{49}$ & 3 & $2.248-3.911$ & $0.124-0.260$ & - & $0.250-0.350$ & $31.4-36.2$ & 14 & $1.10-1.51$ & $488-531$ \\
\hline${\text { Guandalini et } \mathrm{al}^{16}}^{16}$ & 5 & $1.500-6.000$ & $0.096-0.456$ & - & $0.130-0.520$ & $27.7-34.7$ & 16 & $0.32-1.50$ & $520-577$ \\
\hline Guidotti $^{28}$ & 11 & 3.000 & $0.194-0.208$ & - & 0.260 & $31.5-51.7$ & $8-32$ & $0.76-1.62$ & $510-551$ \\
\hline Tassinari $^{62}$ & 2 & 3.000 & $0.196-0.212$ & - & 0.260 & $66.3-67.0$ & 16 & $0.82-1.48$ & $540-552$ \\
\hline Fernández Ruiz et $\mathrm{al}^{4}$ & 1 & 3.000 & 0.210 & - & 0.260 & 34.0 & 16 & 1.50 & 709 \\
\hline Clément $^{63}$ & 3 & 3.000 & $0.346-0.35$ & - & $0.220-0.440$ & $31.6-33.9$ & 16 & $0.75-1.53$ & $520-541$ \\
\hline Lips et $\mathrm{al}^{64}$ & 4 & 3.000 & $0.193-0.353$ & - & $0.130-0.520$ & $30.5-36.5$ & 16 & $1.50-1.63$ & $556-583$ \\
\hline Heinzmann et $\mathrm{al}^{65}$ & 1 & 4.100 & 0.294 & 0.200 & - & 35.5 & 32 & 1.20 & 577 \\
\hline Inácio et al ${ }^{66}$ & 3 & 1.650 & $0.101-0.102$ & - & 0.200 & $35.9-130.1$ & $13.2-13.9$ & $1.24-1.48$ & $523-532$ \\
\hline Einpaul et $\mathrm{al}^{51}$ & 10 & $1.700-3.900$ & $0.197-0.218$ & $0.042-0.330$ & 0.260 & $34.2-44.1$ & 16 & $0.74-1.59$ & $517-542$ \\
\hline${\text { Drakatos et } \mathrm{al}^{67}}^{67}$ & 2 & 3.000 & $0.195-0.200$ & - & 0.390 & $34.3-39.2$ & 16 & $0.80-1.61$ & $507-593$ \\
\hline$\sum$ & 121 & $1.270-6.000$ & $0.096-0.456$ & $0.042-0.451$ & $0.130-0.520$ & $12.8-130.1$ & $4-38.1$ & $0.32-3.70$ & $321-720$ \\
\hline
\end{tabular}

Equation (12), relationship between flexural strength and moment capacity). It enhances the unitary shear strength for small column sizes and decreases it for large column sizes. This is physically consistent, defining a transition for failures in shear in one-way slabs (very large length of the control perimeter $)^{48,49}$ and is acknowledged in design codes (e.g., Reference 7).

It can be noted that Equations (18) and (19) do not explicitly account for the level of deformation of the slab, although it can be back calculated by means of Equation (11). In addition, some of the parameters implied in the equations (as $r_{s}$ and $a$ ) have a physical meaning consistently with the CSCT, and their estimate can be performed with simple geometrical rules for conventional cases, but refined by means of more detailed analyses upon necessity (for design of complex structures or for assessment of critical connections).

It shall also be noted that, as a consequence of the assumptions used to the analytical derivation of the closedform expression of Equation (18), some additional considerations have to be accounted for when using it. These considerations refer to the flexural resistance of squat members and to the location of its control perimeter and are explained in the following.

The first consideration (flexural resistance of squat members) is related with the use of Equation (13) (simplified with Equation (14)) to calculate the moment sectional capacity, which, together with yield-line theory ${ }^{50}$, allows calculating the flexural strength of slender slabs. However, the use of the referred theory to the case of footings has been shown to

TABLE 2 Summary of database with 34 footings without transverse reinforcement subjected to uniform loading: $r_{c}$-radius of a circular column; $c$ - side length of a square column; $d$ —effective depth; $f_{c}$ —cylinders concrete compressive strength; $f_{y}$ —yielding strength of flexural reinforcement; $d_{g}$ —maximum aggregate size; $B$ - size of the footing along orthogonal directions

\begin{tabular}{|c|c|c|c|c|c|c|c|c|c|}
\hline Authors & $\begin{array}{l}\text { Number } \\
\text { of tests }\end{array}$ & $\begin{array}{l}r_{c} \\
(\mathbf{m})\end{array}$ & $c(\mathbf{m})$ & $d(\mathbf{m})$ & $B(\mathbf{m m})$ & $f_{c}(\mathrm{MPa})$ & $\begin{array}{l}d_{g} \\
(\mathbf{m m})\end{array}$ & $\rho(\%)$ & $\begin{array}{l}f_{y} \\
(\mathrm{MPa})\end{array}$ \\
\hline $\begin{array}{l}\text { Dieterle and } \\
\text { Rostásy }^{68}\end{array}$ & 12 & - & $0.150-0.450$ & $0.290-0.760$ & $1.500-3.000$ & $20.1-27.3$ & $30-32$ & $0.21-0.89$ & $395-574$ \\
\hline Hegger et $\mathrm{al}^{52}$ & 8 & - & 0.200 & $0.295-0.470$ & $1.200-1.800$ & $21.1-36.4$ & 16 & $0.82-0.86$ & $528-566$ \\
\hline Siburg and Hegger ${ }^{53}$ & 8 & - & $0.200-0.300$ & $0.400-0.590$ & $1.200-2.700$ & $19.6-53.3$ & 16 & $0.29-0.88$ & $515-627$ \\
\hline
\end{tabular}


TABLE 3 Summary of the results of critical shear crack theory (experimental-to-calculated punching strengths) obtained following different approaches

\begin{tabular}{|c|c|c|c|c|}
\hline Specimens & $\begin{array}{l}\text { Number } \\
\text { of tests }\end{array}$ & Approach & Average & $\begin{array}{l}\text { COV } \\
(\%)\end{array}$ \\
\hline \multirow[t]{5}{*}{ Slabs } & \multirow[t]{5}{*}{121} & Approach (1) ${ }^{\mathrm{a}}$ & 1.07 & 8.3 \\
\hline & & Approach (2) & 1.03 & 8.6 \\
\hline & & Approach $(3)^{\mathrm{c}}$ & 1.04 & 10.0 \\
\hline & & $\begin{array}{l}\text { Approach }(4)^{\mathrm{d}} \text { with } \\
\quad a=V_{\text {flex }} / m_{R}\end{array}$ & 1.03 & 9.7 \\
\hline & & $\begin{array}{l}\text { Approach (4) }{ }^{\mathrm{d}} \text { with } a=8 \\
\text { and } r_{s}=B / 2\end{array}$ & 1.02 & 10.6 \\
\hline \multirow[t]{3}{*}{ Footings } & \multirow[t]{3}{*}{34} & $\begin{array}{l}\text { Approach (3) with } V_{f l e x} \\
\quad \text { calculated with } \rho_{\text {red }}, r_{s}=B / 2\end{array}$ & 0.96 & 9.4 \\
\hline & & $\begin{array}{l}\text { Approach (4) })^{\mathrm{d}} \text { with } a=8 \\
\rho_{\text {red, }} \text { and } r_{s}=B / 2\end{array}$ & 0.95 & 11.5 \\
\hline & & $\begin{array}{l}\text { Approach (4) })^{\mathrm{d}} \text { with } a=8, \rho_{\text {red }} \\
\text { and } r_{s}=B / 2 \geq 2.5 d\end{array}$ & 1.01 & 11.7 \\
\hline
\end{tabular}

a Load-rotation relationship based on quadri-linear moment curvature law ${ }^{13}$ (with the equivalent axisymmetric value of $r_{s}$ calculated from the yield-line value of $V_{f l e x}$ ) and hyperbolic failure criterion (Equation (2)) ${ }^{13}$ with $d_{d g}$ of Equation (7).

${ }^{\mathrm{b}}$ Load-rotation relationship based on quadri-linear moment curvature law ${ }^{13}$ (with the equivalent axisymmetric value of $r_{s}$ calculated from the yield-line value of $V_{\text {flex }}$ ) and the power-law failure criterion (Equation (6)).

${ }^{\mathrm{c}}$ Closed-form solution function of $V_{\text {flex }}$ (Equation (10) with $k_{m}=1.2$ ).

${ }^{\mathrm{d}}$ Closed-form solution function of $\rho$ (Equation (18)). have limitations. ${ }^{30}$ Simões et $\mathrm{al}^{30}$ have used the upper bound theorem of limit analysis to show that the application of yield-line theory ${ }^{50}$ may lead to a significant overestimate of the flexural capacity of compact slabs and footings without shear reinforcement. In those cases, the flexural strength has to be reduced to account for the flexure-shear interaction resulting from the presence of an inclined strut carrying shear which reduces the flexural lever arm. ${ }^{30}$ The assumption that the flexural strength can be approximated as defined in Equation (15) requires thus a reduction of the longitudinal reinforcement ratio when applying Equation (18) to the case of footings or squat slabs without shear reinforcement. A simple expression for these cases is derived in Appendix and results in the following relationship:

$$
\frac{\rho_{\text {red }}}{\rho}=\frac{1-0.5 \cdot \omega \cdot r_{s} / r_{c}}{1-0.5 \cdot \omega} \geq 0.5,
$$

where $\rho_{\text {red }}$ is the reduced longitudinal reinforcement ratio to be introduced in Equation (18) when applying it to the cases of footings without transverse reinforcement; $\omega$ is the mechanical reinforcement ratio $\left(\rho \cdot f_{y} / f_{c}\right) ; r_{c}$ is the radius of a circular column with the equivalent perimeter. (a)

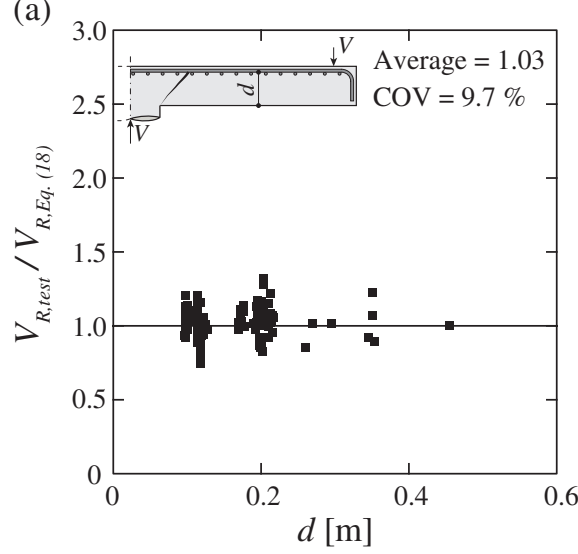

(d)

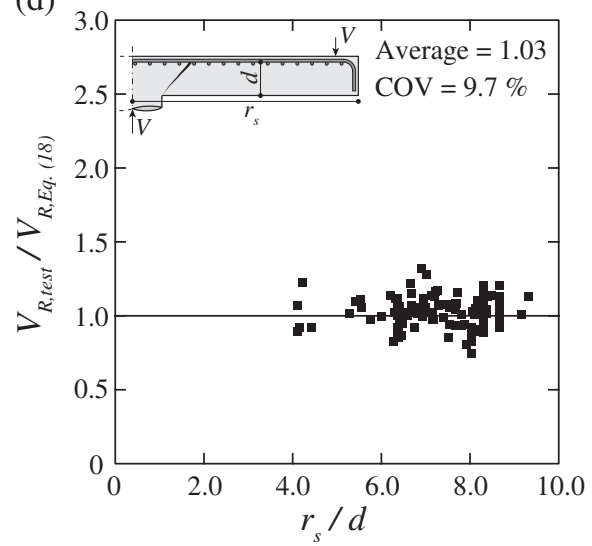

(b)

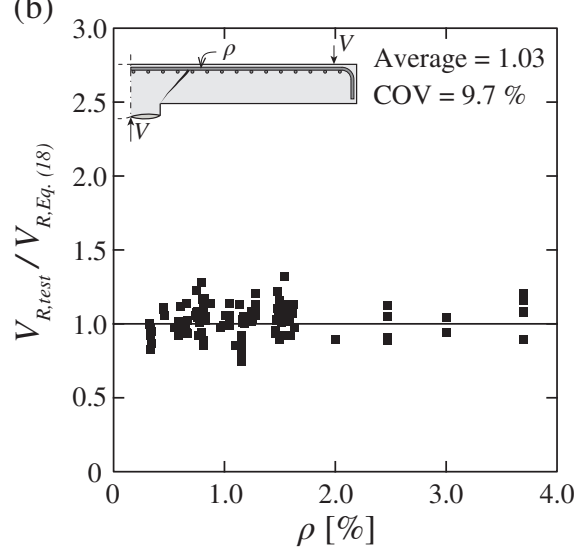

(e)

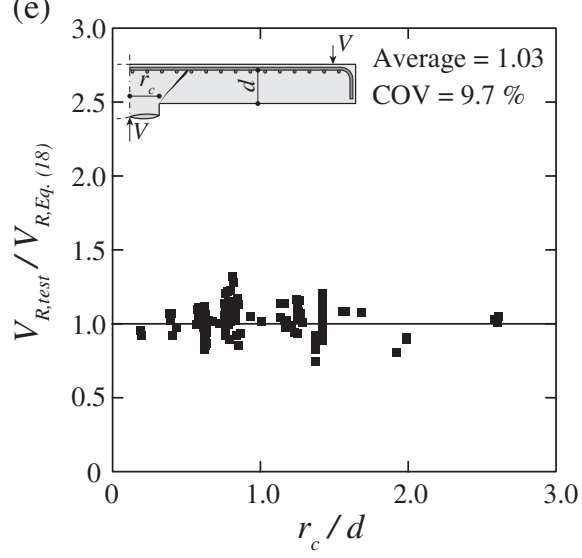

(c)

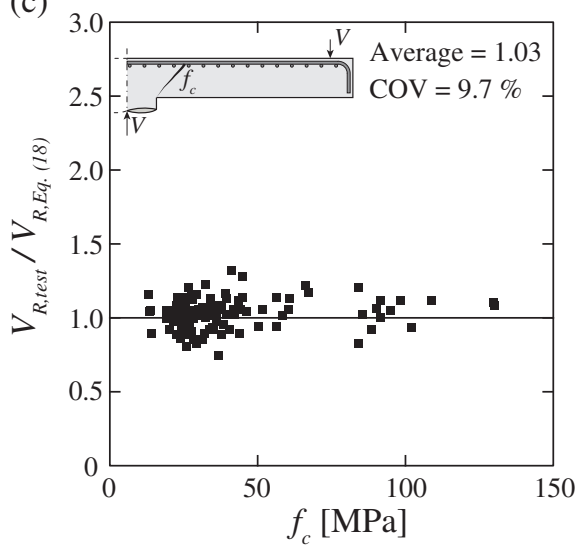

(f)

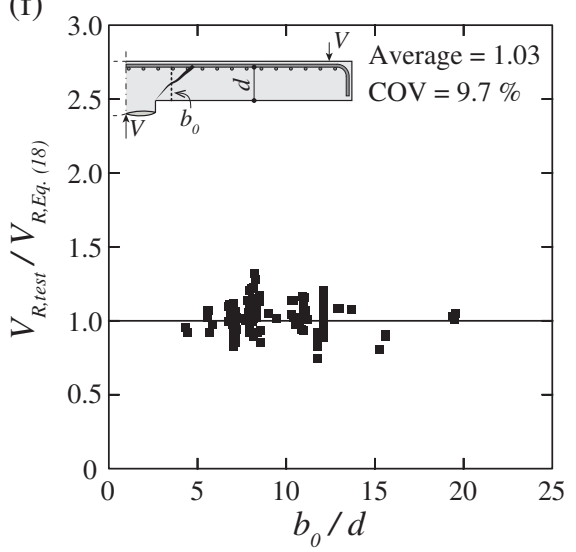

FIGURE 7 Ratio of experimental-to-calculated punching strength according to Equation (18) with $a=V_{f l e x} / m_{R}$ (approach (4)) as a function of: (a) effective depth; (b) flexural reinforcement ratio; (c) concrete compressive strength; (d) radius of the slab-to-effective depth ratio (equivalent $r_{s}$ based on $V_{\text {flex }}$ ); (e) column radius-to-effective depth ratio slabs (equivalent radius of a circular column with equal perimeter for square columns); (f) control perimeter-toeffective depth ratio. Database including 121 specimens without transverse reinforcement (see Table 1) 
The second consideration (location of control perimeter for squat members) results from the fact that Equation (18) considers a constant distance of the control perimeter to the edge of the supported area (control perimeter located at $d / 2$ from the edge). This approach has been shown to be consistent for the case of slender slabs. ${ }^{51}$ For the sake of simplicity, the same distance between the column edge and the control perimeter in the case of footings is also assumed. Nevertheless, as shown by Simões et al, ${ }^{30}$ the location of the control perimeter for squat members should rather be related to the inclination of the failure surface, which is actually a function of geometrical properties. According to this theoretical consideration, with decreasing span-to-effective depth ratio, the inclination of the failure surface tends to be steeper. ${ }^{30}$ In addition, this theoretical consideration has been confirmed also experimentally. ${ }^{27,52,53}$ For consistency, the control perimeter should be shifted to a distance closer than $0.5 d$ in those cases, leading to lower punching resistances. To keep the control perimeter at a distance of $0.5 d$ from the column edge, thus, a lower limit of the distance between the axis of the supported area to the line of zero radial moment $r_{s}$ has to be considered. To that aim, it is suggested to adopt $r_{s} \geq 2.5 d$, corresponding to the limit case where an angle of the failure surface of approximately $45^{\circ}$ has been observed in the analysis of Simões et al. ${ }^{30}$

\subsection{Development of closed-form expressions for slab continuity and compressive membrane action}

An interesting consideration of the CSCT and its derived expressions is that, since the theory is based on a mechanical model, it can be tailored to specific situations by suitably evaluating its mechanical parameters. This is presented in this section with reference to slab continuity and compressive membrane action. As shown by Einpaul et al, ${ }^{20,21}$ this effect might have a significant influence on the (a)

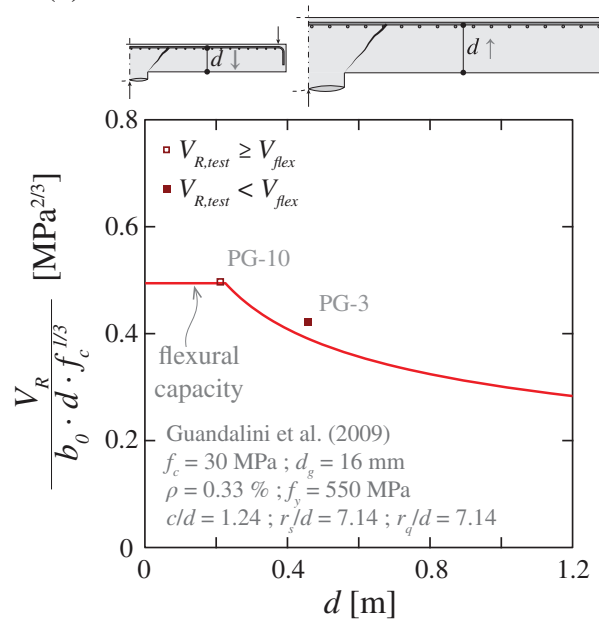

(d)

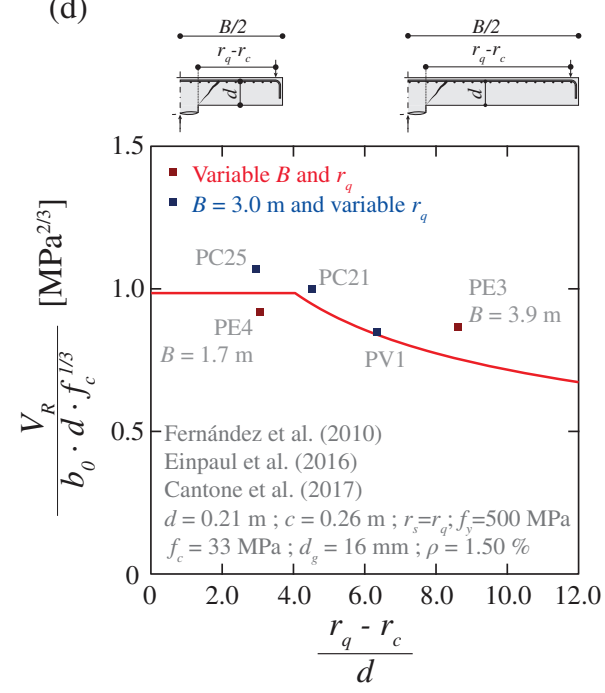

(b)

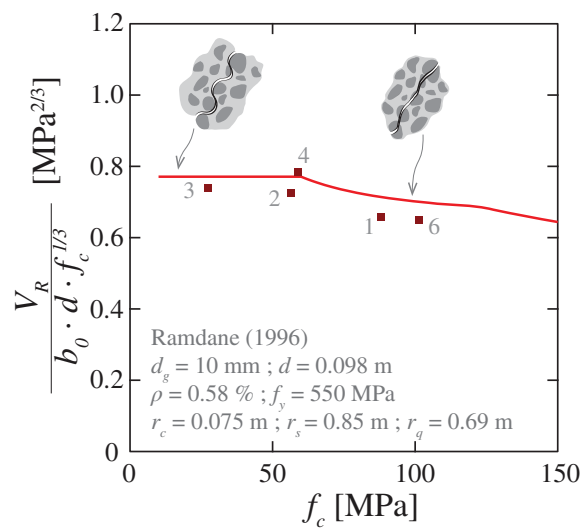

(e)

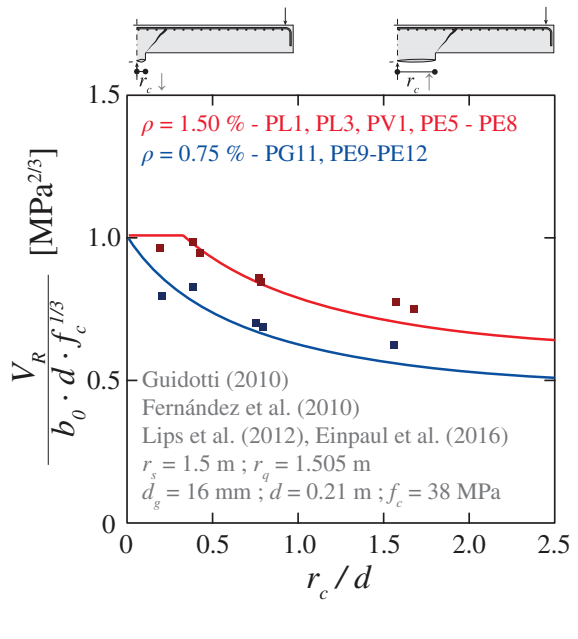

(c)

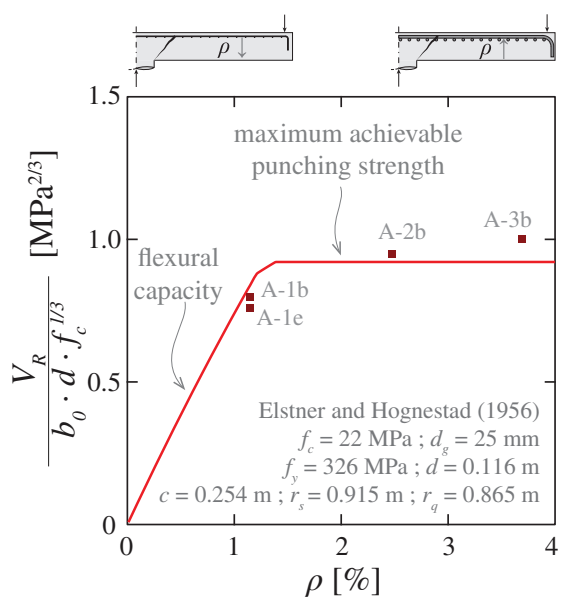

(f)

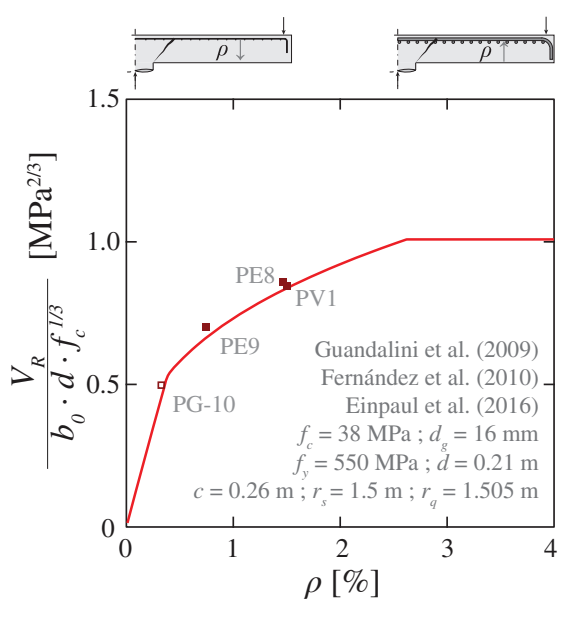

FIGURE 8 Comparison of punching shear resistance according to Equation (18) with different series of experimental results of slabs without transverse reinforcement showing the influence of $\left(a=2 \pi r_{s} /\left(r_{q}-r_{c}\right)\right.$ adopted): (a) effective depth ${ }^{16}$; (b) concrete compressive strength ${ }^{59}$; (c) flexural reinforcement ratio $^{55}$; (d) shear-slenderness as a function of the load introduction ${ }^{4,51,72}$; (e) column radius-to-effective depth ratio ${ }^{4,28,51,64}$; (f) flexural reinforcement ratio $^{4,16,51}$ 
punching behavior and strength of slab-column connections. This phenomenon is relevant particularly for inner connections where compressive in-plane forces may develop around the column area.

The influence of slab continuity and compressive membrane action have been accounted for in the frame of the CSCT by Einpaul et al, ${ }^{20,21}$ by modifying the load-rotation relationship of Equation (1) by means of a factor named $k_{c s}{ }^{21}$ :

$$
\psi=k_{c s} \cdot k_{m} \cdot \frac{r_{s}}{d} \cdot \frac{f_{y}}{E_{s}} \cdot\left(\frac{V}{V_{f l e x}}\right)^{3 / 2} .
$$

As justified by Muttoni and Fernández Ruiz, ${ }^{44}$ factor $k_{c s}$ can be expressed as a function of the ratio $m_{c r} / m_{R}$ (supported on the evidence that the confinement at the column region is provided by the surrounding concrete during the crack development stage) in the following manner):

$$
k_{c s}=\left(0.08 \cdot \frac{m_{R}}{m_{c r}}\right)^{3 / 4} \leq 1
$$

where $m_{c r}$ refers to the cracking moment per unit length. By intersecting the modified load-rotation relationship with the failure criterion, the punching resistance thus results:

$$
V_{R c}=k_{b} \cdot\left(100 \rho \cdot f_{c} \cdot \frac{d_{d g}}{k_{c s} \cdot r_{s}} \cdot\right)^{1 / 3} \cdot b_{0} \cdot d \leq 0.55 \cdot b_{0} \cdot d \cdot \sqrt{f_{c}} .
$$

It can be noted that Equation (23) is analogous to Equation (18), provided that the value of $r_{s}$ is corrected (reduced) to account for the compressive membrane action. Considering that the flexural capacity per unit length $m_{R}$ can be calculated with Equation (14) and that the cracking moment per unit length can be computed as (assuming a ratio $d / h \approx 0.9$ ):

$$
m_{c r}=\frac{h^{2}}{6} \cdot f_{c t} \approx \frac{d^{2}}{0.9^{2} \cdot 6} \cdot f_{c t} .
$$

The factor $k_{c s}$ can be simplified as follows (by introducing Equations (14) and (24) into Equation (22) and rounding exponents and constant values):

$$
\begin{aligned}
k_{c s} & \cong\left(0.08 \cdot \frac{6 \cdot 0.9^{2}}{d^{2} \cdot f_{c t}} \cdot 0.75 \cdot d^{2} \cdot\left(\rho \cdot f_{y}\right)^{0.9} \cdot f_{c}^{0.1}\right)^{3 / 4} \\
\Rightarrow & k_{c s}=k_{4} \cdot \sqrt{100 \rho} \cdot\left(\frac{f_{y}}{f_{c t}}\right)^{3 / 4} \leq 1.0,
\end{aligned}
$$

where the constant $k_{4}=\left(0.08 \cdot 6 \cdot 0.9^{2} \cdot 0.75\right)^{3 / 4} \cdot\left(f_{c} / f_{y}\right)^{3 / 40}$ - $\rho^{7 / 40} \cdot 100^{-1 / 2}$ can finally be simplified as $k_{4}=1 / 75\left(f_{c} \approx\right.$ $30 \mathrm{MPa}, \rho \approx 0.0075$, and $f_{y} \approx 500 \mathrm{MPa}$; low values of the
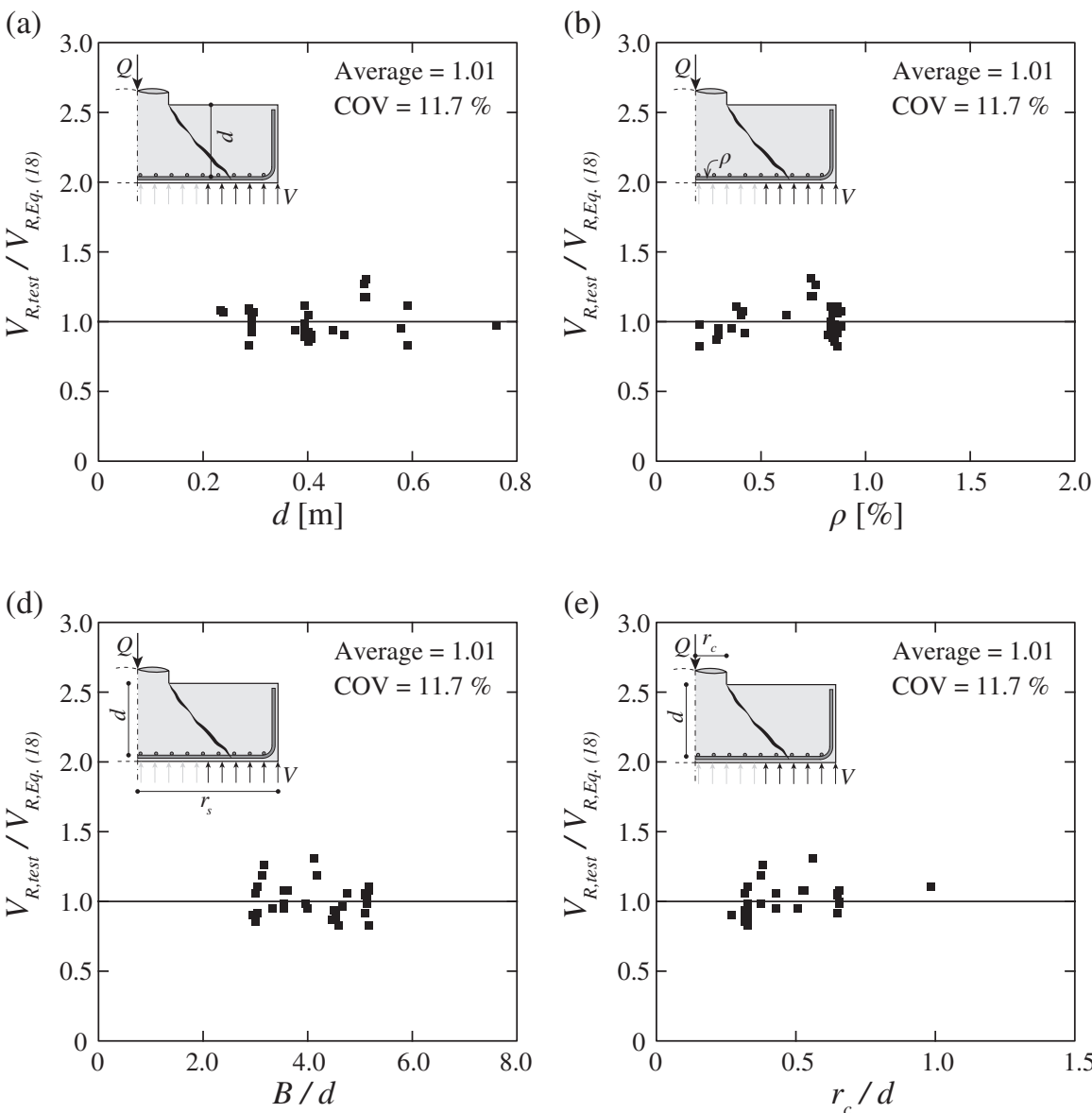

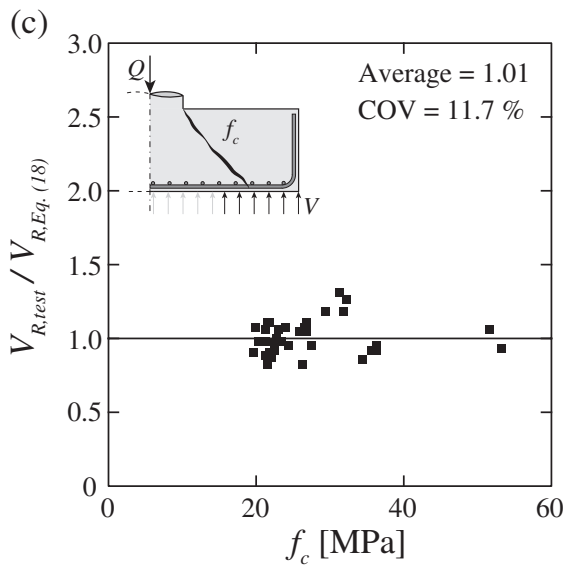

(f)

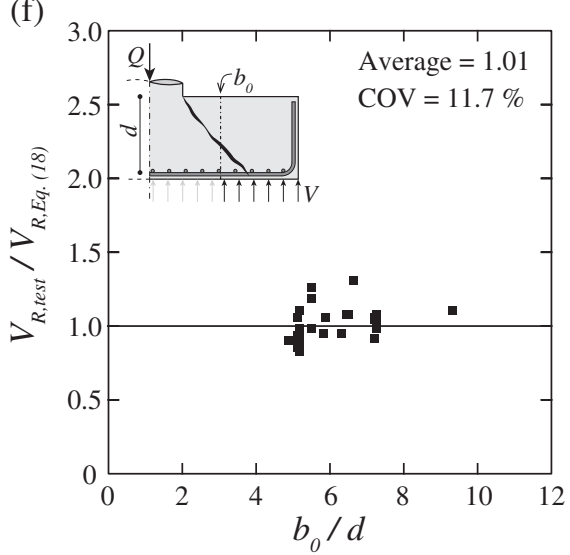

FIGURE 9 Ratio of experimental-to-calculated punching strength according to Equation (18) as a function of $(a=8)$ : (a) effective depth; (b) flexural reinforcement ratio; (c) concrete compressive strength; (d) side length of the footing-to-effective depth ratio; (e) column radius-to-effective depth ratio slabs (equivalent radius of a circular column with equal perimeter for square columns); (f) specimens control perimeter-to-effective depth ratio. Database including 34 footings without transverse reinforcement (see Table 2) 
exponents of $f_{c}, \rho$, and $f_{y}$ lead to a small influence of these variables on the value of constant $k_{4}$ ).

\section{I COMPARISON OF CLOSED-FORM EXPRESSIONS AGAINST EXPERIMENTAL RESULTS}

The accuracy of the CSCT (and more specifically the closed-form design expressions previously derived in Equations (10) and (18)) is compared in this section to available experimental data. For slender slabs, the database considered is that of Einpaul ${ }^{54}$ (update of database of Muttoni ${ }^{13}$ ) but completed with some additional tests. The considered database comprises a total of 121 slender slabs without transverse reinforcement ${ }^{4,8,9,16,28,49,51,55-67}$ (see Table 1 for details). With respect to footings, a database accounting for 34 footings without transverse reinforcement subjected to uniform loading was compiled ${ }^{27,52,53,68,69}$ (see Table 2). Only specimens that do not reach their flexural strength $\left(V_{R \text {,test }}<V_{\text {flex }}\right)$ are included in the databases, as Equations (10) and (18) are only addressed to the shear strength. These databases are consistent with others available in the literature (e.g., References 70 and 71).

Several comparisons to the tests are presented in the following (refer Table 3):

- The first approach (1) corresponds to the original formulation of the CSCT by Muttoni, ${ }^{13}$ accounting for the hyperbolic failure criterion of Equation (2) and the loadrotation curve calculated based on the quadri-linear moment-curvature relationship;

- The second approach (2) corresponds to the power-law failure criterion (Equation (6)) and the load-rotation curve of the slab resulting from the integration of the quadri-linear moment-curvature relationship ${ }^{13}$;

- The third one (3) refers to the closed-form solution as a function of the flexural capacity $V_{\text {flex }}$ (Equation (10); $V_{\text {flex, red }}$ for footings), derived analytically considering the power-law failure criterion and the simplified loadrotation curve of Equation (1);

- Finally, the fourth one (4), refers to the closed-form solution as a function of the flexural reinforcement ratio $\rho$ (Equation (18); $\rho_{\text {red }}$ for footings). (a)

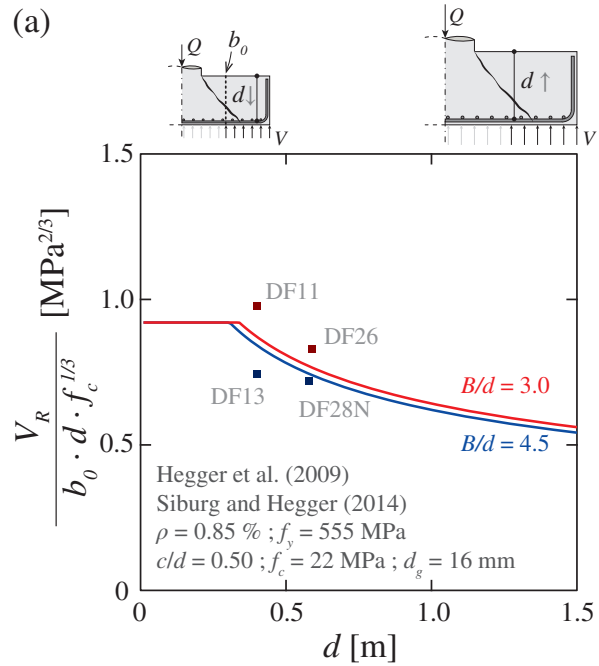

(c)

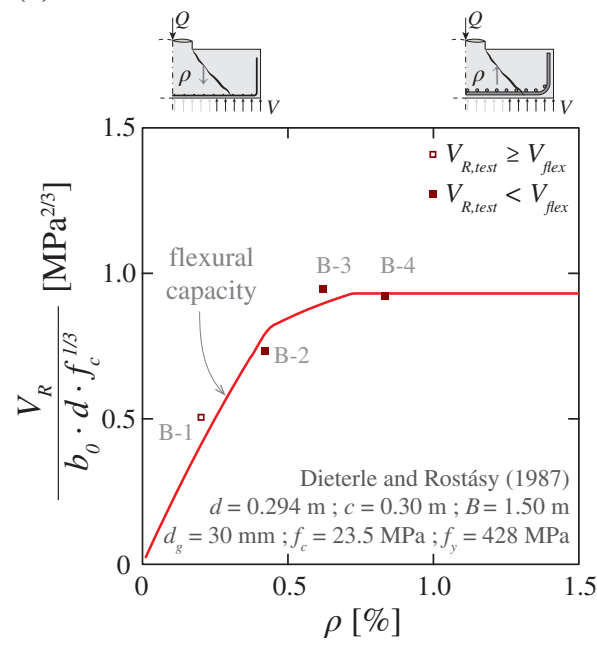

(b)

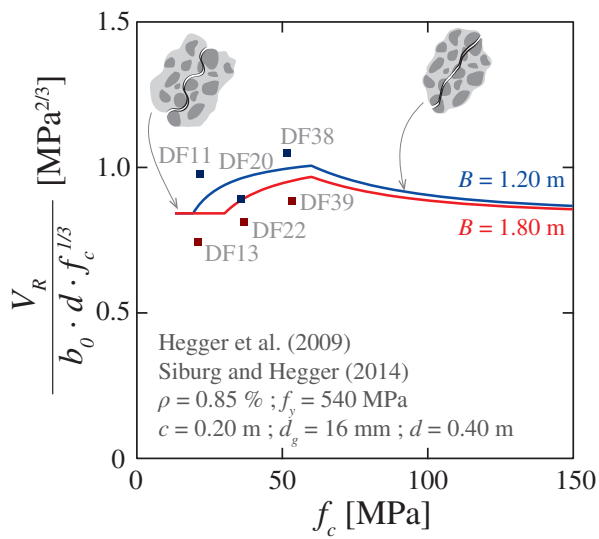

(d)

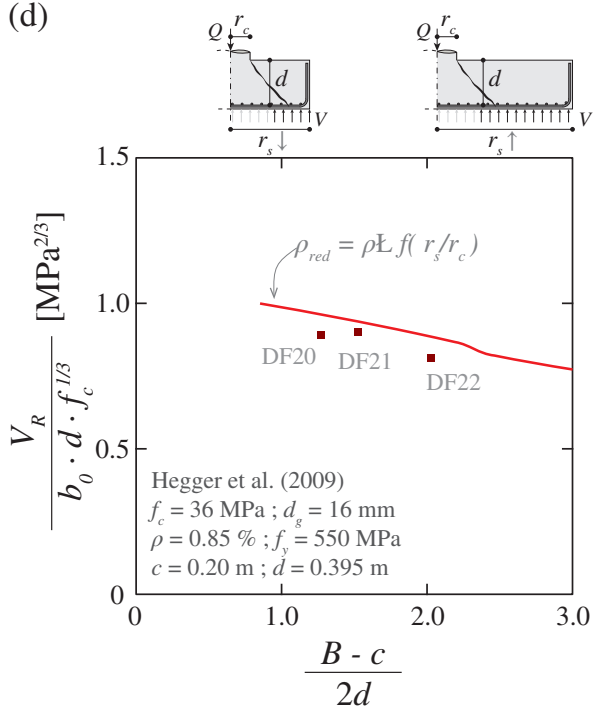

FIGURE 10 Comparison of punching shear resistance according to Equation (18) with different series of experimental results of footings without transverse reinforcement showing the influence of $(a=8)$ : (a) effective depth ${ }^{52,53}$;

(b) concrete compressive strength ${ }^{52,53}$; (c) flexural reinforcement ratio ${ }^{68}$; (d) shear span-to-effective depth ratio ${ }^{52}$ 
The two first approaches are applied only to slender slabs, in accordance to the validity of the derivation of the load-rotation curve based on the quadri-linear momentcurvature diagrams. ${ }^{13}$

\section{1 | Detailed results for slender slabs}

As shown in Table 3, the four approaches yield very similar results in terms of average measured-to-calculated strengths and coefficient of variation (COV). Particularly, very similar results are obtained if, instead of a constant value for parameter $a$ (shear force to average strip moment ratio, $a \approx 8$ ), this value is calculated as defined in Equation (12), with $V_{f l e x}$ determined on the basis of the yield-line theory (see, e.g., References 13,16,50, and 54).

Figure 7 shows the ratio of experimental-to-predicted punching strength obtained with the closed-form expression based on the flexural reinforcement ratio derived from the CSCT (Equation (18)) for the case of slabs without transverse reinforcement. For this comparison, the value of parameter $a$ is calculated according to Equation (12) (using the yield-line theory ${ }^{50}$ to determine $V_{\text {flex }}$ ). The results show that the closed-form expression derived from the mechanical model of CSCT yields consistent results (average of measured-to-calculated values of 1.03 and COV of 9.7\%), without any noticeable trend for the main geometrical and mechanical properties.

A detailed comparison with selected series is also shown in Figure 8 for slender slabs. The various plots refer to the influence of size effect (Figure 8a), the concrete strength (Figure $8 \mathrm{~b}$ ), the flexural reinforcement ratio (Figure $8 \mathrm{c}$ and $\mathrm{f}$ ), the slab slenderness (Figure 8d), and the column size (Figure 8e). The results show that the various failure regimes are suitably reproduced by the closed-form expression and that the trends are finely captured.

\section{2 | Detailed results for footings}

With respect to footings, all results presented in Table 3 are, again, similar. With respect to limiting $r_{s} / d$ to 2.5 , it can be noted that this condition is clearly pertinent (with an average measured-to-calculated strength of 1.01). The results of the closed-form design expression as a function of the reduced flexural reinforcement ratio (Equation (18)) are compared in Figure 9 to the test results considering the lower limit of $r_{s} / d$ to 2.5 (loads applied inside the control perimeter not contributing to the acting shear force). It can be seen that the results are consistent and trend free for the main geometrical and mechanical parameters. As for the slender slabs, the various failure modes are again suitably addressed (Figure 10) as well as the influence of the individual parameters.

\section{6 | CONCLUSIONS}

In this paper, the CSCT is reviewed and used to derive closed-form expressions to calculate the punching shear strength of slabs and footings without transverse reinforcement. The main conclusions of this paper are listed below:

1. The mechanical model of the CSCT can account for different situations where punching failure governs the strength. At failure, localization of the strains in a critical shear crack occurs. The kinematics is governed by a rotation and a shear deformation, and the resulting stresses on the failure surface form an inclined compression strut (whose strength decays for increasing openings of the critical shear crack and lower crack roughness).

2. Slender and squat members are shown to have a different significance of the rotational and shear deformation components at failure. This also influences the failure surfaces and associated strengths. Yet, both can be consistently addressed by the CSCT mechanical model.

3. On the basis of the distinct behavior of slender and squat members, it is justified to adopt a failure criterion characterized by a power law limited by a maximum achievable punching strength.

4. The power-law failure criterion in combination with a load-rotation relationship for the slab allows deriving closed-form expressions for calculation of the punching resistance. The derived expressions provide a clear view of the influence of every parameter and enable the calculation of the punching shear resistance in a direct manner, being therefore suitable for design purposes.

5. The closed-form design expressions can be consistently extended to special cases (as for instance the influence of membrane action), by introducing in the loaddeformation relationship the necessary considerations. This allows deriving physically consistent design expressions for these cases

6. The closed-form expressions derived based on CSCT show an excellent agreement with the experimental results both for slender slabs and squat members (footings) without transverse reinforcement. In addition, the influence of different mechanical and geometrical properties is shown to be consistently considered by the proposed expressions.

\section{NOTATION}

$B \quad$ side length of a square slab

$E_{s} \quad$ modulus of elasticity of flexural reinforcement

$V \quad$ punching shear force

$V_{\text {flex }} \quad$ shear force associated with full yielding of both radial and tangential flexural reinforcement

$V_{\text {flex,red }}$ shear force associated with full yielding of both radial and tangential flexural reinforcement considering flexural-shear interaction

$V_{R} \quad$ punching shear strength 
$V_{R c} \quad$ concrete contribution for punching shear strength

$V_{R, \text { test }}$

$V_{R c, 0}$

$Q_{\text {flex }}$

$Q_{\text {flex,red }}$

a

$b_{0}$

$c$

$d$

$d_{g} \quad$ maximum aggregate size

$d_{g 0} \quad$ reference aggregate size $\left(d_{g 0}=16 \mathrm{~mm}\right.$ for normal weight concrete ${ }^{13}$ )

$d_{d g} \quad$ reference value of the roughness of the critical shear crack

$f_{c} \quad$ concrete compressive strength measured in cylinder

$f_{c e} \quad$ effective concrete compressive strength

$f_{c p} \quad$ plastic compressive strength of concrete

$f_{c c} \quad$ enhanced concrete compressive strength

$f_{y} \quad$ yield strength of flexural reinforcement

$h \quad$ slab thickness

$k_{m}, k_{v}, k_{f c}, k_{1}, k_{2}, k_{3}$ factors

$k_{b} \quad$ shear gradient enhancement factor

$k_{c c} \quad$ factor enhancing concrete compressive strength due to triaxial compression

$k_{c s} \quad$ factor accounting for slab continuity and membrane action

$m_{c r} \quad$ cracking moment

$m_{R} \quad$ average unitary flexural strength in the support strip

$\overline{m_{R}} \quad$ reduced sectional moment capacity

$m_{s} \quad$ average unitary moment for calculation of the bending reinforcement in the support strip

$r_{c} \quad$ radius of a circular column

$r_{0} \quad$ radius of the failure surface at the level of the flexural reinforcement

$r_{s}$ distance of the column axis to the line of contraflexure of bending moments distance of the column axis to the line of load introduction

w crack width

$w_{0} \quad$ initial crack opening due to flexural deformations

height of compression zone due to bending increased height of compression zone due to flexure-shear interaction secant inclination of the failure surface crack sliding global effectiveness factor

$\eta_{f_{c}} \quad$ effectiveness factor accounting for concrete brittleness in compression effectiveness factor accounting for the state of deformations

concrete friction angle angle between failure surface and crack sliding vector flexural reinforcement ratio reduced flexural reinforcement ratio rotation rotation at failure normal stresses due to aggregate interlocking shear stresses due to aggregate interlocking mechanical reinforcement ratio

\section{REFERENCES}

1. Fédération internationale du béton, fib Bulletin 12: Punching of structural concrete slabs, Technical report, Lausanne, Switzerland, ISSN 1562-3610, ISBN 2-88394-052-5; 2001, 314.

2. Polak MA. Punching Shear in Reinforced Concrete Slabs, SP-232, American Concrete Institute, Farmington Hills, MI, USA; 2005:302.

3. Fédération internationale du béton, fib Bulletin 81: Punching shear of structural concrete slabs: Honoring Neil M. Hawkins. Lausanne, Switzerland, ISSN 1562-3610, ISBN 978-2-88394-121-2, 2017:378.

4. Fernández Ruiz M, Muttoni A, Kunz J. Strengthening of flat slabs against punching shear using post-installed shear reinforcement. ACI Struct J. 2010;107(4):434-442.

5. Fernández Ruiz M, Mirzaei Y, Muttoni A. Post-punching behavior of flat slabs. ACI Struct J. 2013;110:801-812.

6. Eurocode 2. Design of Concrete Structures-General Rules and Rules for Buildings, EN 1992-1-1. Brussels, Belgium: CEN European Committee for Standardization; 2004:225.

7. American Concrete Institute Committee 318. Building Code Requirements for Reinforced Concrete (ACI 318-14). Farmington Hills, MI: American Concrete Institute; 2014.

8. Kinnunen S, Nylander H. Punching of concrete slabs without shear reinforcement. Trans Roy Inst Technol. 1960;158:112.

9. Hallgren M. Punching Shear Capacity of Reinforced High Strength Concrete Slabs [Doctoral thesis], Department of Structural Engineering, Royal Institute of Technology, Stockholm, Sweden, TRITA-BKN, Bulletin 23, 1996, 206.

10. Broms CE. Punching of flat plates-a question of concrete properties in biaxial compression and size Effect. ACI Struct J. 1990;87(3):292-304.

11. Broms CE. Tangential strain theory for punching failure of flat slabs. ACI Struct J. 2016;113(1):95-104.

12. Muttoni, A, Schwartz, J. Behaviour of beams and punching in slabs without shear reinforcement. Presented at: IABSE Colloquium; 1991, 62; Zurich, Switzerland, 703-708.

13. Muttoni A. Punching shear strength of reinforced concrete slabs without transverse reinforcement. ACI Struct J. 2008;105(4):440-450.

14. Muttoni A. Schubfestigkeit und Durchstanzen von Platten ohne Querkraftbewehrung [Shear and punching strength of slabs without shear reinforcement] [in German], Beton- und Stahlbetonbau, 98, 2003, 74-84.

15. Fernández Ruiz M, Muttoni A. Applications of the critical shear crack theory to punching of R/C slabs with transverse reinforcement. ACI Struct J. 2009;106:485-494.

16. Guandalini S, Burdet O, Muttoni A. Punching tests of slabs with low reinforcement ratios. ACI Struct J. 2009;106(1):87-95.

17. Fernández Ruiz M, Muttoni A. Size effect on punching shear strength: Differences and analogies with shear in one-way slabs. In: Punching shear test of structural concrete slabs: Honoring Neil M. Hawkins, ACI-fib International Symposium, fib Bulletin 81, 2017, 59-72.

18. Muttoni A, Fernández Ruiz M, Bentz E, Foster SJ, Sigrist V. Background to the Model Code 2010 shear provisions-Part II punching shear. Struct Concr. 2013;14(3):204-214.

19. Muttoni A, Fernández Ruiz M. The Levels-of-Approximation approach in MC 2010: applications to punching shear provisions. Struct Concr. 2012;13(1):32-41. 
20. Einpaul J, Fernández Ruiz M, Muttoni A. Influence of moment redistribution and compressive membrane action on punching strength of flat slabs. Eng Struct. 2015;86:43-57.

21. Einpaul J, Ospina CE, Fernández Ruiz M, Muttoni A. Punching shear capacity of continuous slabs. Farmington Hills, MI, USA: ACI Struct J; 2016:861-872.

22. Maya Duque LF, Fernández Ruiz M, Muttoni A, Foster SJ. Punching shear strength of steel fibre reinforced concrete slabs. Eng Struct. 2012;40:83-94.

23. Faria D, Einpaul J, Pinho Ramos A, Fernández Ruiz M, Muttoni A. On the efficiency of flat slabs strengthening against punching using externally bonded fibre reinforced polymers. Constr Build Mater. 2014;73:366-377.

24. Belletti B, Walraven JC, Trapani F. Evaluation of compressive membrane action effects on punching shear resistance of reinforced concrete slabs. Eng Struct. 2015;95(2015):25-39.

25. Vecchio FJ, Collins MP. The modified compression-field theory for reinforced concrete elements subjected to shear. ACI J. 1986;83(2):219-231.

26. Fernández Ruiz M, Muttoni A, Sagaseta J. Shear strength of concrete members without transverse reinforcement: a mechanical approach to consistently account for size and strain effects. Eng Struct. 2015;99:360-372.

27. Simões JT, Bujnak J, Fernández Ruiz M, Muttoni A. Punching shear on compact footings with uniform soil pressure. Struct Concr. 2016;17(4): 603-617.

28. Guidotti R. Poinçonnement des planchers-dalles avec colonnes superposées fortement sollicitées [Doctoral thesis]; 2010; EPFL, Lausanne, Switzerland, 230.

29. Braestrup MW, Nielsen MP, Jensen BC, Bach F. Axisymetric punching of plain and reinforced concrete, Report No. 75, Structural Research Laboratory, Technical University of Denmark, 1976, 33.

30. Simões JT, Faria DMV, Fernández Ruiz M, Muttoni A. Strength of reinforced concrete footings without transverse reinforcement according to limit analysis. Eng Struct. 2016;112:146-161.

31. Walraven JC. Fundamental analysis of aggregate interlock. ASCE J Struct Eng. 1981;107(11):2245-2270.

32. Hordijk DA. Tensile and tensile fatigue behaviour of concrete, experiments, modelling and analyses. Heron. 1992;37(1):79.

33. Jiang D-H, Shen J-H. Strength of concrete slabs in punching shear. J Struct Eng. 1986;112(12):2578-2591.

34. Bortolotti L. Punching shear strength in concrete slabs. ACI Struct J. 1990;87(2):208-219.

35. Kuang JS. An Upper-bound Plastic Solution for Punching Shear Failure of Concrete Slabs, Report No. CUED/D-Struct/TR.136, Engineering Department, University of Cambridge, UK; 1991, 41.

36. Salim W, Sebastian WM. Plasticity model for predicting punching shear strengths of reinforced concrete slabs. ACI Struct J. 2002;99(6):827-835.

37. Nielsen MP, Hoang LC. Limit Analysis and Concrete Plasticity. 3rd ed. Boca Raton, FL: CRC Press; 2011.

38. Nielsen MP, Braestrup MW, Jensen BC, Bach F. Concrete Plasticity: Beam Shear-Shear in Joints-Punching Shear, Danish Society for Structural Science and Engineering. Copenhagen, Denmark: Structural Research Laboratory, Technical University of Denmark, Special Publication; 1978:129.

39. Braestrup MW. Punching shear in concrete slabs. Presented at: IABSE Colloquium, Plasticity in Reinforced Concrete, No. 28, Copenhagen, Denmark; 1979, 115-136.

40. Hoang LC. Punching Shear Analysis according to the Crack Sliding Model-Slabs without Shear Reinforcement, in: Proceedings of the Danish Society for Structural Science and Engineering, Copenhagen: Danish Society for Structural Science and Engineering; 77, 3, 2006, 69-133.

41. Fédération internationale du béton. fib Model Code for Concrete Structures. Vol 2013. Germany: Ernst \& Sohn; 2010:434.

42. SIA. Code 262 for Concrete Structures. Zürich, Switzerland: Swiss Society of Engineers and Architects; 2013:102.

43. Muttoni A, Fernández Ruiz M. MC2010: the critical shear crack theory as a mechanical model for punching shear design and its application to code provisions, fédération internationale du béton, Bulletin 57; 2010, 31-60.

44. Muttoni A, Fernández Ruiz M. The Critical Shear Crack Theory for punching design: from a Mechanical Model to Closed-Form Design Expressions. In: Punching shear test of structural concrete slabs: Honoring Neil M. Hawkins, ACI-fib International Symposium, fib Bulletin 81, 2017, 237-252.
45. Sherwood EG, Bentz EC, Collins MP. Effect of aggregate size on beamshear strength of thick slabs. ACI Struct J. 2007;104(2):180-190.

46. Muttoni A, Fernández Ruiz M. Shear strength of members without transverse reinforcement as function of critical shear crack width. ACI Struct J. 2008;105(2):163-172.

47. Muttoni A. Die Andwendbarkeit der Plastizitätstheorie in der Bemessung von Stahlbeton [The applicability of the theory of plasticity in the design of reinforced concrete] [in German], Institut für Baustatik und Konstruktion, Report No. 176, ETH Zürich; 1990, 158.

48. Van der Voet AF, Dilger WH, Ghali A. Concrete flat plates with wellanchored shear reinforcement elements. Can J Civ Eng. 1982;9(1):107-114.

49. Birkle G. Punching of Flat Slabs: The Influence of Slab Thickness and Stud Layout [PhD Thesis]; University of Calgary, Calgary, Canada; 2004, 217.

50. Johansen KW. Yield-line Theory. London: Cement and Concrete Association; 1962:182.

51. Einpaul J, Bujnak J, Fernández Ruiz M, Muttoni A. Study on influence of column size and slab slenderness on punching strength. ACI Struct J. 2016;113(1):135-145.

52. Hegger J, Ricker M, Sherif A. Punching strength of reinforced concrete footings. ACI Struct J. 2009;106:706-716.

53. Siburg C, Hegger J. Experimental investigations on punching behaviour of reinforced concrete footings with structural dimensions. Struct Concr. 2014;15:331-339.

54. Einpaul J. Punching Strength of Continuous Flat Slabs [Doctoral thesis], EPFL, Lausanne, Switzerland, No. 6928; 2016, 209.

55. Elstner RC, Hognestad E. Shearing strength of reinforced concrete slabs. ACI Journal Proceedings 1956;53-2:29-58.

56. Moe J. Shearing strength of reinforced concrete slabs and footings under concentrated loads. PCA. 1961;D47, 135.

57. Schaefers U. Construction, Dimensioning and Safety with Respect to Punching Shear of Reinforced Concrete Flat Plates in the Vicinity of Internal Columns [In German: Konstruktion, Bemessung und Sicherheit gegen Durchstanzen von balkenlosen Stahlbetondecken im Bereich der Innenstützen]. Vol 357. Berlin, Germany: Deutscher Ausschuss für Stahlbeton; 1984, 83 , in German.

58. Tolf $P$. Influence of the slab thickness on the strength of concrete slabs at punching. Tests with circular slabs [ In Swedish: Plattjocklekens inverkan på betongplattors hallfasthet vid genomstansning. Försök med cirkulära plattor [in Swedish], Royal Institute of Technology, Department of Structural Mechanics and Engineering, Bulletin 146, Stockholm, Sweden; 1988, 64.

59. Ramdane K-E. Punching shear of high performance concrete slabs. In: Proceedings of the Fourth International Symposium on Utilization of HighStrength/High Performance Concrete. Vol 3. Paris, France: Laboratoire Central des Ponts et Chaussées; 1996:1015-1026.

60. Hassanzadeh G. Strengthening of Bridge Slabs with Respect to Punching: Test Results [In Swedish: Förstärkning av brobaneplattor pa pelaremed hänsyn till genomstansning "Redovisning av provningar"], Report 41. Stockholm, Sweden: Royal Institute of Technology; 1996, 134.

61. Sistonen E, Lydman M, Huovinen S. Teräsbetonilaatan lävistyskapasiteetin laskentakaavan geometrinen malli [The geometrical model of the calculation formula of the punching shear capacity of the reinforced concrete slab] [in Finnish], Report No. 69, Helsinki University of Technology, Espoo, Finland, 1997, 95.

62. Tassinari L. Poinçonnement symétrique des dalles en béton armé avec armature de poinçonnement [Doctoral thesis], EPFL, Lausanne, Switzerland, No. 5030, 2011, 197.

63. Clément $T$. Influence de la précontrainte sur la résistance au poinçonnement des dalles en béton armé [Doctoral thesis], EPFL, Lausanne, Switzerland, No. 5516, 2012, 224.

64. Lips S, Fernández Ruiz M, Muttoni A. Experimental investigation on punching strength and deformation capacity of shear-reinforced slabs. ACI Struct J. 2012;109:889-900.

65. Heinzmann D, Etter S, Villiger S, Jäger T. Punching tests on reinforced concrete slabs with and without shear reinforcement. ACI Struct J. 2012;109(6):787-794.

66. Inácio M, Ramos AP, Lúcio V, Faria DV. Punching of high strength concrete flat slabs-experimental investigation. Eng Struct. 2015;103:275-284.

67. Drakatos I-S, Muttoni A, Beyer K. Internal slab-column connections under monotonic and cyclic imposed rotations. Eng Struct. 2016;123:501-516 
68. Dieterle H, Rostásy F. Deutscher Ausschuss für Stahlbeton [Load-carrying behaviour of isolated reinforced concrete foundations of square columns] [in German]. Tragverhalten quadratischer Einzelfundamente aus Stahlbeton. 1987; 1: 91-387.

69. Hallgren M, Kinnunen S, Nylander B. Punching shear tests on column footings. Nordic Concr Res. 1998;21:22.

70. Walkner R. Kritische Analyse des Durchstanznachweises nach EC2 und Verbesserung des Bemessungsansatze [Critical review of punching shear according to EC2 and improving the design approach] [in German] [Doctoral thesis]: Innsbruck University; 2014.

71. Siburg C. Zur einheitlichen Bemessung gegen Durchstanzen in Flachdecken und Fundamenten [For uniform punching shear design of flat slabs and foundations] [in German] [Doctoral thesis], RWTH Aachen; 2014.

72. Cantone R, Muttoni A. Punching Shear Tests of Flat Slabs. École Polytechnique Fédérale de Lausanne, Structural Concrete Laboratory, Lausanne, Switzerland, Internal report; 2017.

\section{APPENDIX}

A simplified expression to account for a flexure-shear interaction in squat members subjected to uniform pressure is derived in this Appendix for practical purposes. Figure 11 (a) shows a square footing with a side length $B$ subjected to a uniform soil pressure. A square column with a side length $c$ is also considered. The yield-line mechanism governing in this case is considered to be characterized by the formation of a yield line along the edge of the column (see Figure 11 (c)), where the sectional moment capacity calculated in accordance to Equation (13) is reached. According to this mechanism, which corresponds to a pure flexural behavior, the height of the compression zone $x$ is obtained by equalling the horizontal forces developing in the section:

$$
\frac{x}{d}=\omega=\frac{\rho \cdot f_{y}}{f_{c p}}
$$

where $\omega$ represents the mechanical reinforcement ratio. Figure 11(b) shows a possible stress field developing along the axis of the footing (considering that tensile strength is neglected). The stress field consists only of inclined concrete struts which are horizontally equilibrated by the flexural reinforcement. With increasing flexural reinforcement ratio, the area of the inclined struts increases (as well as the region of triaxial stresses developing under the footing). The height of this region becomes very significant and can considerably decrease the lever arm between the horizontal compressive (concrete) and tensile (reinforcement) forces. In addition, provided that tensile strength is neglected, the entire horizontal tensile force has to be equilibrated by the horizontal compressive force under the column. Therefore, for practical purposes and taking into consideration the stress field illustrated in Figure 11(b), a sectional analysis as the one shown in Figure 11(d) can be adopted to calculate a reduced sectional moment capacity $\bar{m}_{R}$ as follows:

$$
\bar{m}_{R}=\rho \cdot f_{y} \cdot d^{2} \cdot\left(1-\frac{\bar{x}}{2 \cdot d}\right),
$$

where $\bar{x}$ represents an increased compression zone accounting for the flexure-shear interaction, which can be computed from the horizontal equilibrium in the section as (tensile force developing along the width of the footing $B$ equilibrated by the compressive force developing along the width of the column $c$ with an enhanced concrete compressive strength due to triaxial compression $\left.f_{c c}=k_{c c} \cdot f_{c}\right)$ :

$$
\frac{\bar{x}}{d}=\frac{\rho \cdot f_{y}}{k_{c c} \cdot f_{c p}} \cdot \frac{B}{c} \leq 1 .
$$

(a)

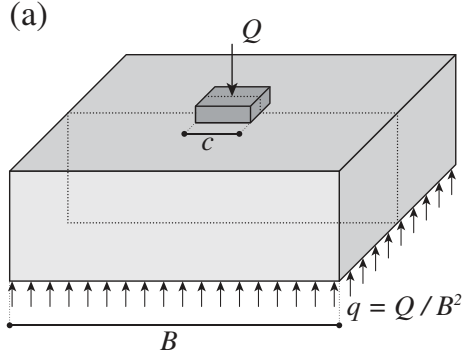

(b)

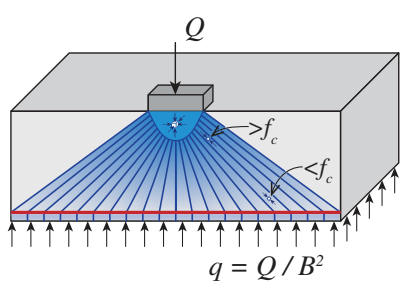

(c)

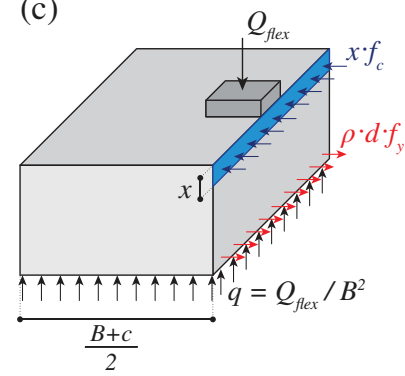

(d)

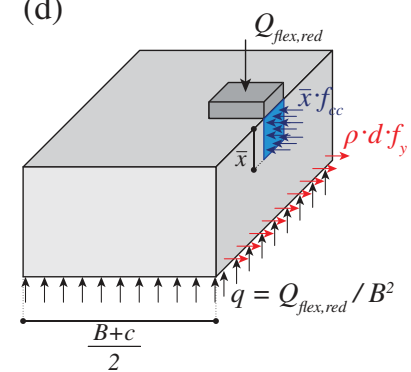

(e)

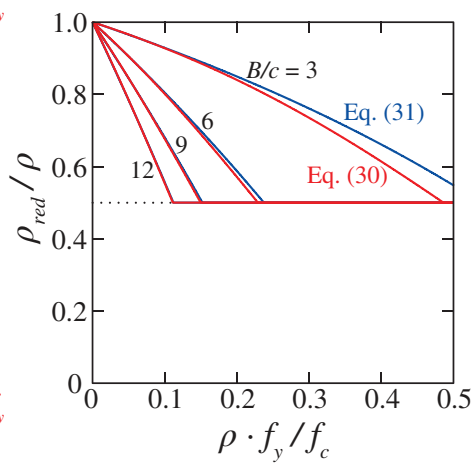

FIGURE 11 (a) Square footing with square column subject to uniform soil pressure; (b) stress field obtained assuming zero tensile strength for concrete; (c) pure flexural failure mode; (d) simplified flexural-shear failure mode; (e) reduction of flexural reinforcement ratio accounting for flexural-shear interaction 
A reduced reinforcement ratio $\rho_{\text {red }}$ accounting for the decrease of the lever arm due to flexure-shear interaction can be calculated equalling the moment capacity established in Equation (13) and the reduced moment capacity defined in Equation (A2) as follows:

$$
\bar{m}_{R}=m_{R} \Rightarrow \rho \cdot\left(1-\frac{\rho \cdot f_{y}}{2 \cdot k_{c c} \cdot f_{c}} \cdot \frac{B}{c}\right)=\rho_{\text {red }} \cdot\left(1-\frac{\rho_{\text {red }} \cdot f_{y}}{2 \cdot f_{c}}\right) .
$$

The solution of interest of the second degree parabola defined in Equation (A4) is given by:

$$
\frac{\rho_{\mathrm{red}}}{\rho}=\frac{1}{\omega} \cdot\left(1-\sqrt{1-2 \cdot \omega \cdot\left(1-\frac{\omega}{2} \cdot \frac{B}{k_{c c} \cdot c}\right)}\right) \geq 0.5
$$

Equation (A5) is nevertheless not convenient for practical purposes. An approximated solution can be simply obtained based on Equation (A4) (assuming that dimension $B$ in Figure 11(a) represents $2 r_{s}$ and replacing dimension $c$ by $2 \pi r_{c} / 4$, where $r_{c}$ represents the radius of a circular supported area with equal perimeter), resulting into:

$$
\frac{\rho_{\text {red }}}{\rho}=\frac{1-0.5 \cdot \omega \cdot r_{s} / r_{c}}{1-0.5 \cdot \omega} \geq 0.5
$$

where $\omega$ is the mechanical reinforcement ratio defined in Equation (A6) (note that, according to its derivation, the limit $r_{s} / d \geq 2.5$ does not apply in this equation). Both exact (considering a beneficial effect of triaxial compression with $k_{c c} \approx 1.3$ ) and approximated solutions yield very similar results, as shown in Figure 11(e). The simplified expression (Equation (A6)) can therefore be applied in practical cases to reduce the longitudinal reinforcement ratio contributing to the punching strength of compact slabs and footings.

\section{AUTHOR'S BIOGRAPHIES}

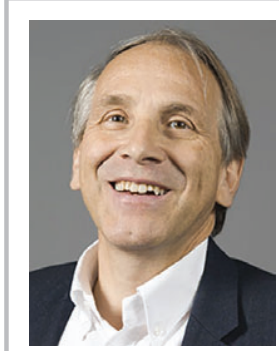

Aurelio Muttoni, PhD Professor

École Polytechnique Fédérale de Lausanne, School of Architecture Civil and Environmental Engineering, Station 18, CH-1015, Lausanne, Switzerland aurelio.muttoni@epfl.ch

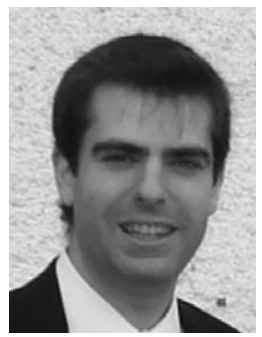

Miguel Fernández Ruiz, PhD Senior Lecturer IBETON

École Polytechnique Fédérale de Lausanne,

School of Architecture Civil and Environmental Engineering,

Station 18, CH-1015, Lausanne,

Switzerland

miguel.fernandezruiz@epfl.ch

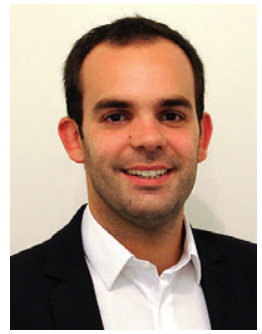

João T. Simões

$\mathrm{PhD}$ Candidate École Polytechnique Fédérale de Lausanne, School of Architecture Civil and Environmental Engineering, Station 18, CH1015, Lausanne, Switzerland joao.simoes@epfl.ch

How to cite this article: Muttoni A, Fernández Ruiz M, Simões JT. The theoretical principles of the critical shear crack theory for punching shear failures and derivation of consistent closed-form design expressions. Structural Concrete. 2017;1-17. https:// doi.org/10.1002/suco.201700088 